\title{
Characterizing the work of coaching during design reviews
}

\begin{abstract}
In this exploratory study we characterize the work of coaching' using a pedagogical content knowledge (PCK) framework to make visible coaches' integrated knowledge of the how, what, and why of coaching during design reviews. We observed four patterns of coaching across three design review contexts: choreography, undergraduate industrial design, and mechanical engineering. These include scaffolding articulation, driving for meaning and guidance, breaking the $4^{\text {th }}$ wall to create a teaching moment, and 'suggest don't tell' to let the student figure it out. We conclude with identifying new ways to conceptualize the work of coaching in design reviews as integrated knowing, situated practice, and shared repertoires.
\end{abstract}

Keywords:

Design education

Design coaching

Pedagogical content knowledge

Design reviews or critiques are a common approach for helping learners in any discipline develop and demonstrate design expertise (Dym, Agogino, Eris, Frey \& Leifer, 2005; Huet, Culley, McMahon \& Fortin, 2007; Goldschmidt, 2002). Some describe the practice of moving from desk to desk explaining what is right and wrong with student work as a ritual of design teaching (Dannels, 2005; Schön, 1993); others, the "bread and butter" of design training (Goldschmidt, Casakin, Avidan \& Ronen, 2014). However, the how, what, and why of coaching during design reviews is considered an underdeveloped area of design research (Goldschmidt et al., 2014). In this paper, "coaching" refers to the dynamic functions, contributions, and roles of individuals who participate in advicegiving situations like a design review. Individuals can include instructors (those who manage a design course or project), experts (those with relevant expertise but who are not stakeholders), stakeholders (individuals or organizations that can affect or be affected by the actions of a designer or team), and peers (those who are members of a design team or class). These functions, contributions, and roles are dynamic because coaches switch functions and roles over the course of a design review in response to different situations, both planned and emergent, and to student needs that call for different coaching contributions (McDonnell, this volume; Reich, Ullman, Van der Loos \& Leifer, 2008). While design reviews are shaped by disciplinary cultures, our use of this term is to represent a continuum of advice-giving interactions ranging from formal to informal and individual to group, and interactions over the duration of a design project such as interim, final and juried reviews (Oh, Ishizaki, Gross \& Do, 2012). 
One perspective on the work of coaching is how coaching during design reviews contributes to student learning, empowerment, identity formation, and socialization into professional practice. During design reviews, coaches direct students in ways to improve designs and processes, guide design reasoning (Ball \& Christensen, this volume; Dong, Garbuio \& Lovallo, this volume), offer advice in making explicit key design decisions with associated rationales and consequences (Huet et al., 2007), control and offer resources (Reich et al., 2014), monitor and intervene with respect to processes and guidelines (Reich et al., 2014), and provide opportunities for students to fail, succeed, and take ownership in design decisions (Yilmaz \& Daly, this volume). Coaches perform their design thinking for students, making visible their accumulated experience, knowledge, and belief systems (Uluoğlu, 2000). Goldschmidt et al. (2010) note that is an understudied "black box" representing a coaches' personal style and accumulated wisdom. Coaches also help students form a design thinking mindset (Dannels \& Martin, 2008) and navigate the non-trivial aspects of learning to use disciplinary knowledge in context (Wolmarans, this volume). Coaches can also empower students to learn how to act independently (Goldschmidt et al., 2014) and construct their own design voice as they socialize students into the complexities and ambiguities of professional practice (Brandt et al., 2013; Howard \& Gray, 2014; Murphy, Ivarsson \& Lymer, 2012; Oak, 2000; Oak \& Lloyd, 2014; McDonnell, this volume).

Other perspectives emphasize the nature of coaching as engaging students in reflective practice, critical discourse, transformative learning, and self-authorship. For example, Schön (1987) characterizes the work of coaching as listening, telling, demonstrating, and imitating. His reflective practice framework formalizes coaching as helping students make sense of their experiences and make explicit their evolving design knowledge through reflection-in-action and reflection-on-action (Schön, 1993). This can help students critically reflect on their design beliefs in ways that support significant learning transformations (Argyris \& Schön, 1974; Mezirow, 2000). In engineering, Dym et al. (2005) characterize design teaching as enabling divergent and convergent reasoning through question-asking discourse. In communication, Dannels and Martin (2008) characterize coaching as design critique discourse focused on judgments, process orientation, brainstorming, interpretation, recommendations, investigations, and identity invocation. Goldschmidt (2006) characterizes instruction in architecture design studios as moving away from knowledge transmission towards empowering students' selfexpression and creativity, which has potential for enabling students' self-authorship as future professionals (Baxter Magolda \& King, 2004).

Reich et al. (2008) found that coaches fulfill a continuum of roles along dimensions of consultative, educational, and motivational functions: problem-focused interventions as either a source of knowledge or an authority figure enforcing guidelines or rules, learning-focused guidance along an educational path to impart knowledge and expertise, and mentoring-focused moral support. Other research illustrates roles like showing the way and being a buddy offering encouragement or "being there" (Goldschmidt, Hochman \& Dafni, 2010; Taylor et al., 2001), inspiring students to take ownership and fostering 
creative tension (Marin et al., 1999), being an expert/authority (Goldschmidt, Hochman \& Dafni, 2010), and modeling design acts to students (Cennamo, Brandt, Scott, Douglas, McGrath, Reimer \& Vernon, 2001). Pembridge (2011) identified additional roles associated with career development such as role model, career mentor, and professional socialization agent.

The ways coaches' structure design reviews that affect the practice of critiquing include the setting (individual/group, formal/informal), types of coaches, and modalities (speech, text, drawing, gestures, artifacts) (Oh et al., 2012). Design reviews may take place opportunistically at a student's desk or at scheduled predetermined phases of a design process within academic settings or at project sites. Design reviews are shaped by disciplinary cultures. For example, architectural and product design critiques often include informal personal critique sessions, group review sessions, and juried reviews (Goldschmidt, Hochman \& Dafni, 2010; Oh et al., 2012) that emphasize improvement (Cardella, Buzzanell, Cummings, Tolbert \& Zoltowski, 2014), process feedback (de la Harp et al., 2009), and direct experience with form, function, and materials (Brandt, Cennamo, Douglas, Vernon, McGrath \& Reimer, 2013). Engineering reviews are often scheduled meetings that emphasize information sharing, feedback, and obtaining approval (Huet et al., 2007).

Research on strategies coaches use to affect learning emphasize "best practices" (Taylor, Magleby, Todd \& Parkinson, 2001). For example, Ledewitz (1985) identified six teaching strategies aimed at developing students' design skills such as experimenting in multiple design cycles, backward design, incremental information dispensing of information, studies of solution types, experiments, and self evaluation. According to Uluoğlu (2000), coaching in architecture studios should include demonstrating how to perform design acts and describing and interpreting design situations. In industrial design, Cennamo et al. (2011) recommend meta-discussions that target deep and potentially transformative learning.

\section{Characterizing the work of coaching}

The $10^{\text {th }}$ Design Thinking Research Symposium involved sharing a dataset to investigate the nature of design reviews and coach-student interactions across multiple contexts and perspectives such as aesthetic, technological, and human-centered design (Adams \& Siddiqui, 2015). Coaches included instructors, experts, peers, and community and industry stakeholders; design reviews were conducted in choreography, entrepreneurship, industrial design, mechanical engineering, and service learning settings. Watching the videos, we were struck by an ability to observe years of design coaching experience in action - coaches' consistency in approaches across students (key messages, concerns, strategies) yet tailoring approaches to student-specific or design-specific needs. We could see how coaches leveraged or created learning opportunities and had a repertoire of strategies for helping students learn design and become designers.

In this paper we conceptualize "the work of coaching" as pedagogical content knowledge (PCK), a framework that makes visible the craft knowledge that guides teaching actions within a subject (Crismond \& Adams, 2012; Driel, Verloop \& Vos, 1998; Shulman, 
1987). This framework offers an integrated perspective encompassing dimensions of coaching functions, contributions, roles, and strategies. We use this framework to characterize the design thinking specific knowledge coaches' use in their moment-tomoment interactions with students during design reviews. In the following sections we describe the conceptual frameworks that shaped this exploratory study and study methods, and present four patterns of coaching observed across three design review environments - choreography, undergraduate industrial design, and mechanical engineering. These patterns include: scaffolding articulation, driving for meaning and guidance, breaking the $4^{\text {th }}$ wall to create a teaching moment, and "suggest don't tell" to let the student figure it out. We conclude with discussing new ways to conceptualize the work of coaching and implications for research and coaching practice.

\section{The work of coaching as pedagogical content knowledge}

Pedagogical content knowledge (PCK) is a learning sciences framework for making visible the craft knowledge that guides teachers' actions in practice (Driel, Verloop \& Vos, 1998; Shulman, 1986; 1987). Craft knowledge refers to the accumulated wisdom of the how, what and why of teaching in a domain (Driel, Verloop \& Vos, 1998). As shown in Figure 1, it is an integrated epistemological perspective that goes beyond considerations of content or pedagogy in isolation from each other to a blending of teacher's knowledge of content and pedagogy (Shulman, 1986). Hill, Ball, and Schilling (2008) conceptualized details of this blending as integrating knowledge of content and students, knowledge of content and teaching, and specialized content knowledge (see Table 1). While this framework has been used predominantly in pre-college or K-12 learning contexts, the idea is applicable to college contexts.

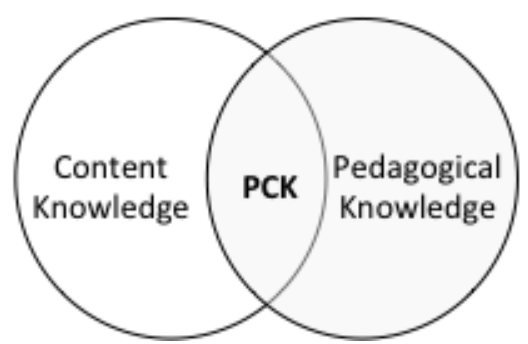

Figure 1. Pedagogical Content Knowledge (PCK) as teacher's intertwined knowledge of content and pedagogy.

<< Figure 1 about here - copied into document to illustrate desired dimensions >>

$<<$ Table 1 about here; it should follow Figure 1 $>>$

Table 1. Key elements of an integrated perspective of pedagogical content knowledge

Knowledge type Examples

Knowledge of Intertwines knowing about content with knowing about how students think about, 
content and students

Knowledge of content and teaching

Specialized content knowledge know, or learn particular content, e.g.:

- Preconceptions and naïve conceptions that students of different ages and background bring with them to learning (Gess-Newsome, 1999; Shulman, 1986)

- Anticipating difficulties students may encounter or inefficient habits of mind as well as typical learning trajectories they may experience (Crismond \& Adams, 2012; Grossman, 1990; Shulman, 1986)

- $\quad$ Predicting what students will find interesting and motivating (Ball, Thames \& Phelps, 2005)

- $\quad$ Being able to interpret students' emerging and incomplete thinking (Ball, Thames \& Phelps, 2005; Gess-Newsome, 1999)

- $\quad$ Setting relevant learning goals (Crismond \& Adams, 2012)

Intertwines knowing about content with an understanding of the issues that affect student learning, e.g.:

- $\quad$ Strategies to help students develop depth of understanding and make connections including knowing when to pose new questions or tasks to deepen students' understanding (Drier et al., 1998; Hynes, 2012; Veal et al., 1998)

- Useful examples or powerful analogies for representing ideas including real-world examples that make it link to students' lives or learning styles (Ball, Thames \& Phelps, 2005; Davis, 2003; Gess-Newsome, 1999; Magnusson, Krajcik \& Borko, 1999; Shulman, 1986)

- $\quad$ Being able to evaluate the advantages or disadvantages of instructional strategies for teaching a specific idea (Ball, Thames \& Phelps, 2005; Gess-Newsome, 1999)

Teacher knowledge of content but not requiring knowledge of students or teaching, e.g.:

- Resembles content of curriculum but emphasizes how teachers developed own fluency in a content area (Ball et al., 2005) and what teachers need to know to be able to do the work assigned to their students (Hill et al., 2008)

- $\quad$ Being able to unpack the elements of content knowledge to make its features apparent to students (Ball et al., 2005; Hill et al., 2008)

- Often experience-based knowledge associated with knowing concepts, practices, applications, and the nature of inquiry (Ball et al., 2005)

Design PCK can be a lens for investigating and characterizing the work of coaching during design reviews (Adams, Forin, Chua \& Radcliffe, 2014); Crismond \& Adams, 2012). Design PCK is a design thinking version of the ideas in Table 1 that makes visible coaches' (1) intertwined knowledge of design and how students learn or conceptualize design as way of knowing and being, (2) intertwined knowledge of design with an understanding of the issues that affect student learning of design, and (3) specialized design thinking knowledge that coaches demonstrate and make apparent to their students.

While PCK research has a rich history in science education and teacher professional development (Ball, 1996; Grossman, 1990), it is a relative newcomer in technology education and design education. As a recent example, Hynes (2012) investigated design teaching in middle school and found that teachers use prototypes and iteration as a form of design PCK to help students clarify or identify new needs or imagine future versions. Phillips et al. (2009) used the PCK construct to create a subject matter taxonomy that could serve as a content guide for industrial design education. Mishra and Koehler (2006) have conducted numerous studies to conceptualize Technology PCK, a model that parallels the ideas in Table 1 but articulates unique aspects such as the ways teachers use technology to teach technology. 
Using a PCK construct to investigate the work of coaching in design reviews offers many benefits for advancing research and professional development frameworks, as well as facilitating research-to-practice cycles (Mishra \& Koehler, 2006). Broadly, PCK has offered research frameworks for analyzing the evolution of a curriculum, characterizing discourse associated with curriculum and instruction, and making predictions about the conditions of good teaching practice that impact student learning (Mishra \& Koehler, 2006). For design researchers, it provides a science of learning perspective that complements existing research characterizing the nature of design and the nurture of design learning. For example, reflective practice (Schön, 1993) may be conceptualized from a PCK perspective as integrating knowledge of design as reflective practice with knowledge of how to train designers to reflect in and on their design practice. PCK also provides frameworks for professional development by offering a language for teachers to notice and reflect on what may be present or missing in a curriculum, and supporting teachers' reflective practice and developing teacher knowledge of a complex web of elements that may be thoughtfully integrated into education (Mishra \& Koehler, 2006). A particular motivation for this study was leveraging the benefits of a PCK framework for making coaches' knowledge of design-specific coaching practices visible and public as a mechanism for enhancing design instruction. Finally, PCK frameworks support connections between research and practice by assuring that discussions of content are relevant to instructional practices and that discussions of instruction retain attention to content (Ball et al., 2005).

\section{Investigating the work of design coaching}

This study utilizes a shared dataset of design review conversations - digital videos of conversations between those who give and those who receive feedback, guidance, or critique during a design review event (Adams \& Siddiqui, 2015; Adams, 2015). The dataset includes longitudinal data across six contexts comprised of 86 digital videos, accompanied by time-stamped transcripts and copies of design work documents. Here, context refers to the setting of the design review as shaped by disciplinary (e.g., mechanical engineering in a college of engineering, industrial product design in a college of arts) and cross-disciplinary perspectives (e.g., service-learning involving teams of students from different disciplines), and student characteristics (e.g., undergraduate to graduate level). The full dataset includes variations in review structures (e.g., one-on-one and group critiques, informal and formal reviews), phases (preliminary to final reviews), disciplinary cultures (choreography, entrepreneurship, industrial design, mechanical engineering, and service learning), design coaches (instructors, peers, external experts, and stakeholders), and student level.

This study follows a PCK approach similar to Ball et al. (2005) to characterize the work of coaching as observed in the moment-to-moment demands of design reviews: what coaches do and how what they do conveys or reflects an understanding of design, design learners, and effective design instruction. As shown in Table 2, five principles were used to select data from the larger dataset: (1) inclusive of disciplinary variation to enhance fidelity of study findings across variations in design review events along a continuum of aesthetic to technical perspectives, (2) longitudinal data to follow the same student or 
team over time (e.g., early, interim, and final reviews), (3) substantive coach-student dialogue to have sufficient data for identifying coaching patterns, (4) focus on undergraduate learners in their third (junior) and final year (senior) to see how coaches socialize students into design thinking, and (5) focus on instructors as coaches (as compared to peers, external experts, and stakeholders). The inclusion of choreography in this study was based on three criteria: the data met the five inclusion criteria above, the choreography tasks met criteria identifying critical invariants of design task environments (Goel \& Pirolli, 1992; Daly, Adams \& Bodner, 2012), and the design review structures map to critical variations of review situations (Oh et al., 2012). The entrepreneurship, service-learning, and graduate level industrial data did not meet the inclusion criteria.

$<<$ Table 2 about here $>$

Table 2. Study participants

\begin{tabular}{|c|c|c|c|c|c|}
\hline Discipline & Structure & $\begin{array}{l}\text { Longitudinal } \\
\text { Data }\end{array}$ & Interaction & $\begin{array}{c}\text { Undergraduate } \\
\text { Learners }\end{array}$ & Coaches \\
\hline Choreography & $\begin{array}{l}\text { Group sessions with } \\
\text { coaches taking turns with } \\
\text { references to prototypes } \\
\text { (performances) }\end{array}$ & $\begin{array}{c}\text { First, Second \& } \\
\text { Third Reviews }\end{array}$ & $\begin{array}{l}\text { Learners being } \\
\text { reviewed as } \\
\text { individuals }\end{array}$ & $\begin{array}{l}\text { Elena \& Anita } \\
\text { (Seniors in } \\
\text { final year) }\end{array}$ & $\begin{array}{l}\text { Claire, } \\
\text { Hannah, } \\
\text { Mia, } \\
\text { Rachel, } \\
\text { Sophie }\end{array}$ \\
\hline $\begin{array}{l}\text { Industrial } \\
\text { Design }\end{array}$ & $\begin{array}{l}\text { One-on-one sessions in } \\
\text { shared studio space with } \\
\text { references to prototypes, } \\
\text { sketches, reports }\end{array}$ & $\begin{array}{l}\text { First, Second \& } \\
\text { "Looks Like" } \\
\text { Reviews }\end{array}$ & $\begin{array}{l}\text { Learners being } \\
\text { reviewed as } \\
\text { individuals }\end{array}$ & $\begin{array}{c}\text { Todd \& } \\
\text { Sheryl } \\
\text { (Juniors in } 3^{\text {rd }} \\
\text { year) }\end{array}$ & Gary \\
\hline $\begin{array}{l}\text { Mechanical } \\
\text { Engineering }\end{array}$ & $\begin{array}{l}\text { Formal and informal } \\
\text { presentations with } \\
\text { instructor questions with } \\
\text { references to prototypes, } \\
\text { sketches, reports }\end{array}$ & $\begin{array}{c}\text { Conceptual } \\
\text { Design \& Final } \\
\text { Design } \\
\text { Reviews, Class } \\
\text { Debrief }\end{array}$ & $\begin{array}{l}\text { Learners being } \\
\text { reviewed as a } \\
\text { team }\end{array}$ & $\begin{array}{l}\text { Robot Fish } \\
\text { Team } \\
\text { (Seniors in } \\
\text { final year) }\end{array}$ & Nelson \\
\hline
\end{tabular}

Because only limited information is available regarding coach expertise or knowledge, this is not a focus of this study. All coaches had graduate degrees and were faculty or lecturers in a discipline associated with one or more of their degrees. Within the data, there are indicators of years of experience with being a design coach or a designer. For example, the mechanical engineering coach, Nelson, has a $\mathrm{PhD}$ in mechanical engineering and is a full professor in the program; he often refers to his experience as a designer in industry as part of his coaching. Similarly, the industrial design coach, Gary, is a lecturer in the program, and often refers to design precedents as well as his own experience as a professional product designer. The choreography coaches all have advanced degrees; like the students in the dataset, they also designed choreography for the winter dance program, and during the design reviews reference prior choreography projects and historical precedents.

\subsection{Making Visible Elements of Design PCK}

The purpose of this study is to make visible the how, what, and why of coaching during design reviews through a design PCK lens. Figure 2 illustrates the frameworks used for 
making visible individual elements of design PCK and for analyzing combinations of these elements as intertwined patterns of design PCK.

Two pre-existing frameworks relevant for design review situations were used to observe and characterize approaches to coaching in design reviews that affect student learning (right side of Figure 2): cognitive apprenticeship and teaching as improvisation. As observable teaching techniques, they make visible the "how" of coaching in design reviews; as teaching techniques grounded in extensive research on how people learn, they make visible some of the "why" aspects of coaching in design reviews that affect student learning. To observe and characterize the "what" and "why" elements of coaching in design reviews, we used three frameworks to make visible the design thinking knowledge coaches seek to convey, demonstrate, make apparent, and encourage in their students (left side of Figure 2): design judgment (conceptual knowledge) and design task and process management strategies (procedural knowledge). In particular, a pre-existing framework that contrasts beginning and informed design behaviors (Crismond \& Adams, 2012) was used to observe and characterize "what" coaches want students to learn about design in terms of "why" students progress as learners from beginning to informed designers. The following paragraphs and tables summarize key aspects of these coding frameworks.

<< Figure 2 about here, included in text to show desired dimension $>>$

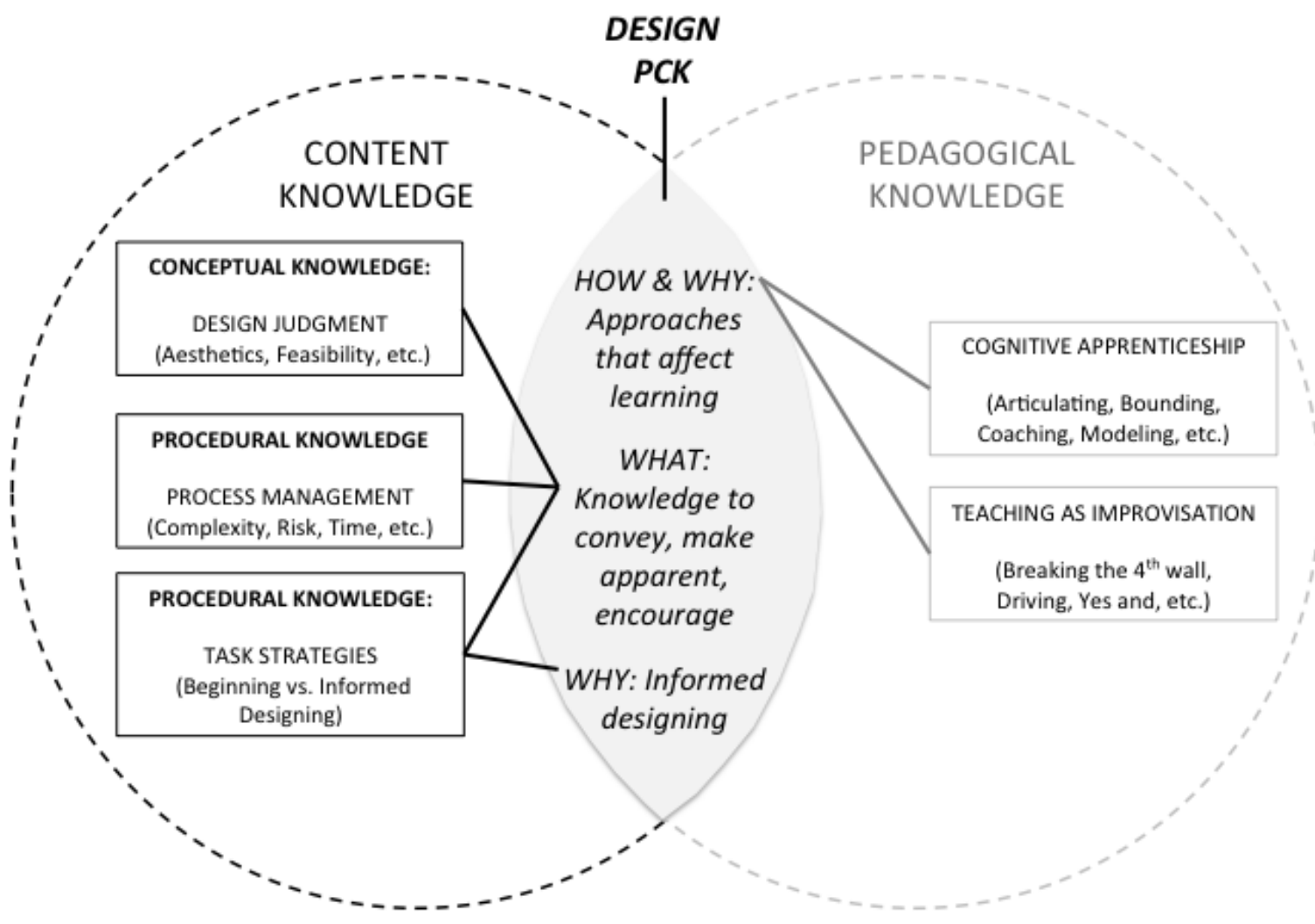


Figure 2. Frameworks for making visible elements of coach's design PCK in design reviews.

Illustrated in Figure 2 as the overlap between content and pedagogical knowledge, these individual frameworks can be combined to reveal patterns of design PCK that intertwine the how, what, and why of coaching in design reviews. Similar to Table 1, this can include: knowledge of content and students that intertwines design thinking knowledge with how students learn or conceptualize design as a way of knowing and being, knowledge of content and teaching that intertwines design thinking knowledge with an understanding of issues that affect student learning of design, and specialized design thinking knowledge that coaches demonstrate and make apparent to their students. By taking this approach we sought to overcome some of the challenges inherent in the complexity of the PCK construct where boundaries between knowledge types can be blurry and difficult to discern (Hill et al., 2008).

\subsubsection{How and Why of Design Coaching: Cognitive Apprenticeship and Teaching as Improvisation}

Cognitive apprenticeship theory emphasizes how humans learn in a social manner by observing senior members in one's community of practice (Collins, Brown \& Holum, 1991). Since cognitive activity is not visible by default, teachers of intellectual subjects work at "making thinking visible" or "the externalization of processes that are usually carried out internally... to bring these tacit processes into the open" (Collins et al., 1991, p. 6). In other words, making their metacognition visible to learners in a community of practice. In a design review, a coach's actions may seem mysterious to students: why did a coach like or dislike an element of a student's design, or how would they go about the same task? By making visible the underlying thinking behind decision-making and judgment processes, cognitive apprenticeship techniques help students examine and develop their own decision-making and judgment processes as junior practitioners in the field. While cognitive apprenticeship is not often cited in design thinking research, it fits a tradition of design education as apprenticeship (Cross, 2006) and is synergistic with studies promoting teacher modeling of design thinking values and strategies as a dialectical process with students (Goldschmidt, 2006; Oxman, 1999; Schön, 1993), scaffolding of divergent-convergent thinking combinations (Dym et al., 2005), and constructivist approaches to design teaching (Andjomshoaa, Islami \& Mokhtabad-Amrei, 2011). Table 3 identifies observable techniques coaches (as masters of a cognitive craft) could use with their apprentices (students). As a note, the code of coaching refers to a specific cognitive apprenticeship technique: how a coach makes his or her own thinking about a student's past performance visible such as providing feedback after watching a student perform. The topic of this paper, the work of coaching, is an expansive view that includes all the cognitive apprenticeship activities in Table 3 . To reduce confusion, italics will be used to distinguish when coaching is used as a code.

$<<$ Table 3 about here >>

Table 3. Cognitive apprenticeship codes (Collins et al., 1991).

Cognitive

APPRENTICESHIP DESCRIPTION 
ARTICULATING Student makes their thinking visible to the coach (role reversal of modeling) such as explaining or justifying their performance so a coach can check their reasoning.

COACHING Coach makes their thinking about a student's past performance visible to a student such as watching students perform and providing feedback.

MODELING Coach makes their thinking visible to the student such as demonstrating a target skill or concept while thinking out loud about their process.

REFLECTING Student makes their thinking visible by comparing their process to an expert's process.

SCAFFOLDING Coach makes their thinking about a student's future performance visible to the student (helping make the students' thinking visible) such as directing the student towards a potential problem or subset of a task (a next step or future homework) or encouraging a student to finish a partially completed task.

Teaching as improvisation builds on Sawyer's (2011) idea of adaptive teachers as skilled improvisers. Here, teaching is analogous to improvisational acting: it is unpredictable, contingent upon interactions, and built from moment to moment but draws upon an existing repertoire of pedagogical patterns (Borko \& Livingston, 1989; Sawyer, 2004). This aligns with a "knowledge is emergent" mindset for learner-centered and constructivist approaches to facilitate learners' development of inquiry skills and individual creativity (Brennan, 2013). When there is no script to follow, students are allowed to be self-organizing, leading their own experiences and shaping the flow of teaching interactions (Crossan, 1998; Sawyer, 2008). Teaching as improvisation is a useful design PCK language because it links the nature of design teaching to the nature of design activity as an iterative process (Adams, Atman \& Turns, 2001) marked by opportunistic deviations (Ball \& Ormerod, 1995) and co-evolutionary cycles (Dorst \& Cross, 2001). For example, in a study of expertise Goldschmidt (2006) described the process of translating and conveying knowledge to students during design critiques as highly adaptive to the student and situation, rather than a place of teacher-directed synthesis or a consistent script. Table 4 identifies observable teaching as improvisation techniques (Beghetto, 2009; Sawyer, 2011; Vass, Littleton, Miell \& Jones, 2008). Teaching as improvisation codes not observed were removed from the coding scheme (listen and remember, endowing, and playwriting).

$\ll$ Table 4 about here $>$

Table 4. Teaching as improvisation codes (e.g., Sawyer, 2011)

\begin{tabular}{ll} 
CODES & DESCRIPTION \\
\hline \hline BREAKING THE $4^{\mathrm{TH}}$ & $\begin{array}{l}\text { Breaking an interaction dynamic to settle a conversation at the end of its allotted } \\
\text { time or meta-communicating an important point such as a concept or "ground rule" } \\
\text { that has intrinsic value for the person or field of inquiry. } \\
\text { BenIAL } \\
\text { Breaking an interaction dynamic by rejecting what another has introduced into a } \\
\text { dramatic frame or performance space (the opposite of the Yes, and code). } \\
\text { Taking over an interaction, not letting others talk or contribute (video may need to } \\
\text { be reviewed for corresponding physical cues such as pauses, body language, } \\
\text { authoritative tone, etc.). } \\
\text { Affirming what another has introduced into the dramatic frame or performance space } \\
\text { (such as accepting an assertion or revoicing and building on an assertion), allowing a }\end{array}$ \\
\hline \hline
\end{tabular}


dialogue of collaboration to emerge and flow.

\subsubsection{What and Why of Design Coaching: Conceptual and procedural design knowledge}

Facilitating design thinking rests on helping learners develop two inseparable knowledge types: conceptual and procedural knowledge (Anderson, 1976; Goldschmidt, 2006; Star, 2000). Conceptual knowledge is knowledge of declarative concepts, facts, and principles that govern a domain and the relationships that lead to an integrated conceptual understanding of a domain of knowledge (Anderson, 1976). For design thinking, conceptual knowledge might include principles that shape design judgment (Christensen \& Ball, this volume; Lidwell, Holden \& Butler, 2003), the ways disciplinary cultures shape what knowledge or values are used to develop and judge design ideas (Carvalho, Dong, \& Maton, 2009), and domain-specific knowledge of precedent, materials, tools, laws, and skills (Purcell, 2003).

The coding scheme in Table 5 represents the language coaches in this study used to judge design decisions. Codes were generated using the constant comparison method (Ryan \& Bernard, 2003) with a goal of identifying codes inclusive of all contexts. The constant comparison method is a way of searching for similarities and differences by making systematic comparisons across units of data. This is a process of asking, "what is this unit of data about, and how is it similar or different from others or what does it remind me of elsewhere in the broader dataset?" (Lincoln \& Guba, 1985). This approach generates an inclusive space of categories across disciplines, rather than privileging a single disciplinary perspective. Generated codes complement other research of design judgment values across contexts (Carvalho, Dong \& Marton, 2005; Christensen \& Ball, this volume). They also embody domain-specific knowledge (Wolmarans, this volume): in the mechanical engineering context judging feasibility may involve applying physical laws, calculating maximum or minimum values, and generating sketches or simulations to model performance; in the industrial design context judging interactivity may involve using ergonomic rules or heuristics and drawing on precedent to imagine features that enhance usability.

$<<$ Table 5 about here >>

Table 5. Design judgment conceptual knowledge codes.

\begin{tabular}{|c|c|}
\hline CODES & DESCRIPTION \\
\hline AESTHETIC & $\begin{array}{l}\text { Artistic appeal (e.g., visual, auditory, and sensory), aesthetic principle (e.g., } \\
\text { authenticity, simplicity, purity, etc.) or embodying a sense of beauty (shape, color, } \\
\text { rhythm, texture, symmetry, contrast, organic, space, variation, juxtaposition, etc.). }\end{array}$ \\
\hline COHERENCE & $\begin{array}{l}\text { An integrated or cohesive system, a sense of completeness, or embodying a } \\
\text { designer's perspective or passion. }\end{array}$ \\
\hline FEASIBILITY & $\begin{array}{l}\text { Feasible technical or human performance, or viable (e.g., easy to afford, easy to } \\
\text { realize or make). }\end{array}$ \\
\hline INTERACTIVITY & $\begin{array}{l}\text { Practicality or experience of a design (e.g., ergonomic features, easy to use, multi- } \\
\text { functionality or adaptability to different situations, enjoyable, etc.). }\end{array}$ \\
\hline NOVELTY & Unique, evolutionary, opens up new markets or meets future needs. \\
\hline
\end{tabular}


(UN)PredictabiLITY A dramatic, unexpected, unpredictable, or counterintuitive experience (an aesthetic goal); in contrast, a sense of certainty or predictability (a feasibility goal).

Procedural knowledge is knowledge of how to perform or operate in a situation, and these procedures or action sequences may be simple or multi-faceted with attributes of routine competencies and intelligent performance (Anderson, 1976; Star, 2000). For design, procedural knowledge may be described as task knowledge (generally applicable techniques or heuristics for accomplishing tasks) and process management knowledge (general approaches for directing one's solution process) (Anderson, 1976). One framework that provides a language for task knowledge is a cross-disciplinary scholarship of integration framework on design task behaviors teachers could encourage (or discourage) in helping students learn to design (Crismond \& Adams, 2012). This framework is comprehensive, represents a breadth of design cognition research, and focuses on a developmentally appropriate stage of expertise for undergraduate design education, "informed designing". An informed designer is one whose level of experience includes some formal training in design and level of competence lies in a midrange expertise stage similar to an "advanced novice" and "competent performer" (Dreyfus \& Dreyfus, 1986; 2005) in ways of perceiving, interpreting, structuring, and solving complex problems (Lawson \& Dorst, 2009). This provides a language for characterizing task strategies coaches may convey or encourage during a design review to help students become informed designers (see Table 6). As an example, for the design task strategy of "balance tradeoffs" beginning designers are prone to ignore complexity and trade-offs and make design decisions without weighing all options or attending only to pros of favored ideas or cons of lesser approaches. In a design review, coaches may discourage these behaviors, and encourage or demonstrate behaviors such as using words and graphics to describe and attend to both pros and cons, articulating design values, and making selections that take into account multiple criteria. As another example, for "managed iteration" coaches may encourage students to design in a managed way where ideas are improved upon iteratively through feedback, or discourage or counteract behaviors such as designing in haphazard ways or having a linear process.

$<<$ Table 6 about here $>>$

Table 6. Task and process management procedural knowledge codes.

TASK CODES

PROBLEM FRAMING

IDEA FLUENCY

DEEP MODELING
COACH ENCOURAGES AND/OR DEMONSTRATES BEHAVIORS TO HELP A STUDENT... Comprehend important features of the problem. May discourage or counteract behaviors such as treating design as well-defined and prematurely attempting problem-solving.

Learn about the problem or how the system works. May discourage or counteract behaviors such as skipping doing research and building solutions immediately.

Generate and work with lots of ideas. May discourage or counteract behaviors such as working with few or just one idea, which they can get fixated or stuck on. Inquire into how ideas work, function, or could be made (e.g., prototyping). May discourage or counteract behaviors such as superficial drawings or models.

BALANCE TRADEOFFS Judge options and make decisions that acknowledge both benefits and tradeoffs. 


\begin{tabular}{|c|c|}
\hline VALID EXPERIMENTS & $\begin{array}{l}\text { May discourage or counteract behaviors such as attending only to pros or cons. } \\
\text { Conduct valid experiments to substantiate design decisions. May discourage or } \\
\text { counteract behaviors such as doing few or no tests on prototypes, or running } \\
\text { confounded experiments that cannot provide useful information. }\end{array}$ \\
\hline $\begin{array}{l}\text { FOCUSED } \\
\text { DIAGNOSTICS }\end{array}$ & $\begin{array}{l}\text { Identify problematic aspects and propose ways to improve, fix, or build on them. } \\
\text { May discourage or counteract behaviors such as unfocused and non-empirical } \\
\text { diagnoses that cannot provide useful information for improvements. }\end{array}$ \\
\hline MANAGED ITERATIVE & $\begin{array}{l}\text { Do design in a managed way where ideas are improved iteratively through } \\
\text { feedback. May discourage or counteract behaviors such as designing in haphazard } \\
\text { ways or having a linear process. }\end{array}$ \\
\hline REFLECTIVE & $\begin{array}{l}\text { Reflective practice (e.g., listening to "situation's backtalk", self-monitoring } \\
\text { behavior, assessing the value or relevancy of design strategies). May discourage } \\
\text { or counteract behaviors such as tacit designing with little self-monitoring or not } \\
\text { being open or willing to reflecting on past. }\end{array}$ \\
\hline $\begin{array}{l}\text { PROCESS } \\
\text { MANAGEMENT CODES }\end{array}$ & COACH ENCOURAGES AND/OR DEMONSTRATES BEHAVIORS TO HELP A STUDENT... \\
\hline $\begin{array}{l}\text { COMPLEXITY } \\
\text { MANAGEMENT }\end{array}$ & $\begin{array}{l}\text { Manage complexity such as revisiting or negotiating scope of work, and assessing } \\
\text { feasibility within a timeline. }\end{array}$ \\
\hline RISK MANAGEMENT & $\begin{array}{l}\text { Anticipate and attend to risks associated with planning, communicating, or } \\
\text { developing a design. }\end{array}$ \\
\hline TIME MANAGEMENT & Manage time to successfully complete tasks within a prescribed timeframe. \\
\hline $\begin{array}{l}\text { MULTIPLE } \\
\text { PERSPECTIVES }\end{array}$ & $\begin{array}{l}\text { Manage plurality of perspectives to develop own perspective and having a } \\
\text { tolerance and appreciation for ambiguity. }\end{array}$ \\
\hline SUGGEST DON'T TELL & Exercise and have agency in design judgment under ambiguous circumstances. \\
\hline
\end{tabular}

Table 6 identifies codes for task and process management strategies coaches demonstrate, convey, or encourage with their students. The nine task strategies map to the nine informed designing behaviors (Crismond \& Adams, 2012). The five process management codes were generated from the data using the constant comparison method (Ryan \& Bernard, 2003) and represent strategies for directing an overall solution approach.

\subsection{Data Analysis}

Analysis occurred over five iterative cycles. The first three cycles focused on coding individual elements of design PCK (Tables 3 through 6) and recording these in a qualitative data analysis software system. First, codes for cognitive apprenticeship and teaching as improvisation techniques were applied by watching videos together and discussing codes to agreement. This was followed by a cycle of testing and refining task strategy codes, with an iterative process of generating design judgment and process management codes. The third cycle involved refining and simplifying the codebooks for each framework. Codebooks included a description for each code and example quotes that represent evidence of the code (Lincoln \& Guba, 1985). These were used to clearly and consistently apply codes. After resolving all codebook issues, the team re-coded the transcript data and recorded final coding decisions in Dedoose, a web-based computerassisted qualitative data analysis software. Coding was allowed to co-occur to catalogue interactions between the how, what, and why elements of design coaching as illustrated in Figure 2. In other words, an excerpt of transcript data might have evidence of multiple 
codes - such as scaffolding, articulating, focused diagnostics, and risk management - and these co-occurrences signify interactions among the how, what, and why of coaching in design reviews.

The fourth and fifth cycles involved moving from coding individual elements of design PCK (Figure 2) to identifying, analyzing and naming patterns that intertwine the how, what, and why of coaching in design reviews. The Dedoose software automatically generates diagrams that mark episodes of co-occurring content and pedagogy codes. The team also marked episodes that generated considerable discussion during the coding process. Triangulating between Dedoose and team generated lists, the team prioritized a subset of episodes for analysis. Inclusion was based on the extent to which the nature of an episode was observed in multiple contexts, and the quality of an episode for illustrating and establishing evidence of a pattern. This resulted in 31 examples (5 of Todd, 6 of Sheryl, 6 of Anita, 10 of Elena, and 4 of the Robot Fish Team). The fifth cycle involved discussing examples until robust design PCK patterns emerged that were consistent across the dataset. Patterns and examples within a dataset were named using a coach's own words (where possible), and descriptions that emphasize predominant codes among the co-occurrences. Because of this, three of the four observed patterns have names that emphasize teaching approaches, and one emphasizes a process management strategy.

\section{Four patterns of design PCK}

We observed four patterns of design PCK across disciplinary context and design review structures as summarized in Table 7. All patterns, with the exception of driving for meaning and guidance in the choreography context, were prevalent across all contexts and design review structures. In the following sections we provide one illustrative example for each pattern, using italics to signify codes from Tables 3 through 6 and authentic quotes (with pauses, incomplete sentences, etc.) to explain and provide evidence for each pattern. Other examples are available (Adams, Forin, Chua \& Radcliffe, 2014). Because the coaches in this study had a formal instructor role, the terms "instructor" and "coach" are used interchangeably. We also discuss each pattern from PCK and design thinking and learning perspectives.

$<<$ Table 7 about here $>$

Table 7. Summary of design PCK patterns as "the work of coaching"

SCAFFOLDING TO HELP STUDENTS ARTICULATE AND EVALUATE THEIR REASONING - coach directs a student's attention to an aspect of their design or plan, encouraging the student to articulate their reasoning so they can scaffold deeper inquiry and understanding of design thinking knowledge (e.g., offering alternative language or examples, encouraging particular strategies). Illustrative example: Choreography - "what does the title have to do with the piece?"

DRIVING FOR MEANING AND GUIDANCE - coach takes control of a review dynamic to help a student make conceptual connections or see fallacies or limitations in their design thinking (e.g., drawing on prior knowledge or precedent, offering alternative language or examples, encouraging iteration). Illustrative example: Mechanical engineering - "You're gonna need an O-ring" 
BREAKING THE $4^{\text {TH }}$ WALL TO CREATE A TEACHING MOMENT - coach seeks to convey knowledge of design thinking, habits of mind, or strategies that for students may be unfamiliar, abstract, counterintuitive, conflict with prior beliefs or conceptions, or difficult to recognize as central to designing and becoming a designer. Illustrative examples: Choreography - "Ideas are generative, right?" [situated reflection-inaction] and Mechanical engineering - "So why did you not stay on schedule?" [intentional reflection-onaction]

SUGGEST DON'T TELL TO LET THE STUDENT FIGURE IT OUT - coach anticipates difficulties or limitations in thinking students may encounter in regards to navigating complexity and ambiguity, and provides guidance to help students make their own informed decisions and develop their own voice as designers (e.g., helping them see, express, judge, and reflect upon design intentions and processes). Illustrative examples: Industrial design - "He's gotta discover that"

\subsection{Scaffolding to help students articulate and evaluate their reasoning}

A frequent observation across reviews was the cognitive apprenticeship technique of articulating, where a coach encourages a student to explain and justify their process or performance so they can check a student's reasoning. For example, a choreography coach asked a student, "That's an interesting choice, why do you want to do that?" In this dataset, $72 \%$ of the 47 instances of coaches asking students to articulate their reasoning also involved scaffolding. In some cases, scaffolding involved directing a student towards a focal point or subset of a larger task; in others, coaches combined scaffolding with modeling (a coach making their own reasoning visible). In this way, the design PCK pattern of scaffolding articulation involves a coach scaffolding (directing) a learner's attention to an aspect of their design or plan, as a means for helping that learner articulate (explain and justify their reasoning) and potentially reflect on their approach. While scaffolding articulation was observed to co-occur with teaching as improvisation techniques, this was less frequent (13 instances of which half were Yes, and). Coaches directed students' attention to all design judgment (with the exception of novel), task strategy, and process management strategy codes.

The following scenario, "what does the title have to do with the piece?", is from the choreography context, a semester long course where undergraduate students worked independently to design a dance piece for a public performance. Students chose the concept for the piece and could modify it over time as it took shape. They were responsible for selecting performers, creating their own dance composition and movement vocabulary, and managing sound, lighting, costume and set design. Works-inprogress were presented at three separate company showings. After each showing, students participated in informal reviews with five experienced dance instructors and choreographers (Claire, Hannah, Mia, Rachel and Sophie). The reviews were in a small classroom with tables and chairs in a loose circle. Each coach took a 5-7 minute turn to comment on student work. This example is from Anita's second of three reviews, where the coaches focused on how Anita's combination of early ideas (movements, music, and lighting) were coming together as a synthesized dance work. It illustrates a coach scaffolding articulation to direct a student's attention on issues of aesthetics and coherence in relation to problem framing task strategies to help bring problems and solutions into greater alignment. 
During this review Mia (coach) directs Anita to explain the reasoning behind the title for her design, "Purlicue". First, Mia scaffolds Anita's attention to a perceived lack of coherence between the title and her choreography: "I wondered what the title has to do with your piece...so is it the tension, is it the spatial juxtaposition...?" Anita responds, asking if she should "talk about it". Mia encourages Anita to articulate her reasoning while providing additional scaffolding by directing attention to her concerns about how others may experience confusion over the meaning of the title (interactivity).

Mia:
When you told us your title you said what it meant and so I wondered what the title has
to do with your piece. Because I'm just, okay, all right, so is it the tension, is it the
spatial juxtaposition or the relationship, because students -.
Wnita:
Mould you like me to talk about it?
Yeah, because I'm just gonna tell you, my students won't know what that means, and
so they'll whip out their phones and they'll look up this word and then they're gonna
see it at the dictionary and they'll just space the distance between their thumb and their
forefinger and then they're gonna go, hmm. So I was just curious why you chose this
title.
I mean for me, like this, this idea that first of all there is a definition for this word and
to me this was very gestural and articulate, like looking at the distance, you know,
'cause you have to be very precise and measuring that, and that has something to do
with the hands and the hands are something that I'm working with. And I'm looking at
the word purlicue and the way you write it and the way the letters are formed and the
way you say it on your tongue is very - you know, it has that rounded flowy-ness to
maybe that -
Kind of feminine.
Yeah, it sort of fits into the aesthetic that I have in my head for my piece. And so it
sort of like, you look at it and it makes sense, and if you like were told to like look it
up, it was like, oh, this is like a thing, you know, this is like a thing, this is a thing even
though it doesn't - you don't use it, you know, you don't measure things in purlicues
but it's a thing. So.

Anita explains how the intentionality of the title embodies a gestural aesthetic that emphasizes the use of the hand as a form of measurement or precision, and the "rounded flowy-ness" of the word itself in terms of "the way the letters are formed and the way you say it on your tongue." Mia builds on Anita's reasoning (using Yes, and) to describe this aesthetic as "kind of feminine." Anita affirms and builds on Mia's assertion (Yes, and) by explaining how that aesthetic has coherence with the idea "in my head for my piece. And so it sort of like, you look at it and it makes sense." Anita continues with articulating another aspect of her reasoning, emphasizing the authenticity of the concept, that "this is like a thing, even though...you don't measure things in purlicues but it's a thing." While this is only a brief excerpt as part of an ongoing conversation, it illustrates a coach's use of scaffolding in combination with articulating to reveal Anita's emerging (and perhaps incomplete) reasoning about her title in relation to her choreography choices. It also illustrates a coach providing examples such as an imagined user experience and a "spatial juxtaposition" or "feminine" aesthetic to help Anita consider the deeper meaning of her concept encouraging problem framing to bring the title and the choreography into greater alignment as a coherent experience.

There were similar examples of coaches' scaffolding articulation in the mechanical engineering and industrial design reviews. These often began with the coach asking a 
question that directed students' attention towards a specific area to help a student reason through a design decision. As an example, during the Robot Fish team's formal conceptual design review slide presentation, the mechanical engineering instructor asked: "Hold on just a second. I wanna ask - I wanna go back just second. What prevents the fish from um taking a nose-down attitude when it's just going horizontal?" The coach then scaffolded articulation to direct the team to focus diagnostics on issues of feasibility to troubleshoot solution performance. The industrial design reviews were typically oneon-one informal interactions between the instructor, Gary, and a student. They occurred either at a desk at the front of a shared studio space or at a student's desk. During Todd's first review Gary worked side-by-side with the student to select the five best concepts among a variety of idea sketches. For one idea, an interactive "stacking idea" for an ottoman, Gary asked how the individual layers of the ottoman would be held together so a user could change its shape: "No, now explain that. How would - what would use for mechanical, would this be Velcro or something, or what?" Gary then scaffolded articulation on issues of interactivity and feasibility, encouraging deep modeling strategies to help Todd reason through how this solution could be used or made.

These examples illustrate scaffolding to help students articulate reasoning as a way to access and interpret learners' thinking and guide them toward deeper understanding. From a learning perspective, directing attention to potential design problems and guiding inquiry on these problems can support learners in moving from tacit knowing to reflective practice (Crismond \& Adams, 2012; Schön, 1993), moving beyond surface level to more principled understandings (Chi, Glaser \& Farr, 1988), and managing complexity by narrowing attention to smaller sub tasks (Dreyfus \& Dreyfus, 1985). This pattern was frequently observed in early design reviews where reports, rough sketches and prototypes offered entry points for coaches to see and examine student reasoning. In industrial design and choreography, the prototypes (dance movements, sketches, foam models) and informal structure offered opportunities for coaches to probe reasoning embodied in works-in-progress and co-design with students via Yes, and techniques. In the mechanical engineering context, the formal presentation slides that articulated students' decisions provided a different kind of entry point to probe student reasoning and scaffold further inquiry. This pattern was also observed in design debriefs and final reviews where coaches asked student to reflect on their understanding of design practice.

From a PCK perspective, this pattern makes visible coaches' intertwined knowledge about design with knowing how students think about design and the difficulties they may encounter (see Table 1). In the choreography and industrial design examples, the coaches asked targeted questions to help students' notice and reason through their emerging and incomplete reasoning about aesthetics, coherence, feasibility, and interactivity. In the mechanical engineering example, the instructor (as coach) asked questions to draw students' attention to a potential feasibility issue - the buoyancy of the robot fish. This pattern also illustrates coaches' intertwined knowledge about design with knowledge about how to affect student learning such as combining scaffolding-articulating-modeling techniques to help students develop depth of understanding and inquire into and reflect upon their design decisions - e.g., encouraging problem framing and iteration around issues of aesthetics and coherence in choreography, focused diagnostics on feasibility 
issues in mechanical engineering, and deep modeling and focused diagnostics on feasibility and interactivity issues in industrial design. Coaches' knowledge of design is made visible through the reasoning they demonstrated and the language they used to evaluate ideas (design judgment codes) and the task strategies they encouraged. This pattern complements other findings from the shared dataset that characterizes design coaching as sharing linguistic routines with students (Howard \& Gray, 2014), helping students see what is missing in their design (Cardella et al., 2014), and collaborative codesigning (Yes, and) where a coach elaborates on a student's comments (Yilmaz \& Daly, this issue).

\subsection{Driving for meaning and guidance}

In the mechanical engineering and industrial design reviews, the instructors often took control of a review (the teaching as improvisation technique of driving) to help a student make conceptual connections, consider fallacies or limitations in their design thinking, or broaden the space of alternatives for addressing problematic situations. In some cases, coaches encouraged problem-focused strategies like problem framing, doing research, and idea fluency; in others, solution-focused strategies like deep modeling, focused diagnostics, and balance trade-offs. In almost all cases, coaches encouraged iteration. Driving often co-occurred with modeling (a coach making their reasoning visible), scaffolding (a coach directing attention to a problem and offering suggestions), and breaking the $4^{\text {th }}$ wall (a coach breaking an interaction to communicate an important concept). Of the 19 instances of this pattern, almost all involved a coach breaking the $4^{\text {th }}$ wall, and there were three times as many co-occurrences of driving with modeling as compared to scaffolding. Driving was not explicitly observed in the choreography reviews, although the turn-taking review structure may be perceived as a form of driving.

An illustrative example from the mechanical engineering context, "You're gonna need an O-ring", involves the instructor, Nelson, using driving in combination with coachingmodeling-scaffolding and breaking the $4^{\text {th }}$ wall techniques to direct the Robot Fish team to focus diagnostics on two feasibility concerns: a watertight seal and an electronic system that is easy to access and troubleshoot. This occurred during a conceptual design review in front of the whole class with the team presenting formal slides (e.g., problem definition, requirements, computer-aided drawings, performance analyses, plans and budgets) for about a half hour and Nelson sitting in the back with a copy of the team's report. The goal was to obtain budget approval to finish the working prototype, an aquatic robot designed to study underwater habitats. The scenario begins with Nelson interrupting Yori's explanation of the electronic system. Nelson drives to model focused diagnostics on the PVC tube that houses the electronic system: "Okay, back into the PVC tube that you put the electronics in, we're probably gonna need an O-ring seal...it's when you put that together." Yori responds by asserting that the seal is "already tight". This begins a sequence of interruptions where Nelson drives the review, using a combination of techniques to draw students' attention to limitations in their thinking and to offer other alternatives.

First, Nelson uses scaffolding to help students see the need for a watertight seal that allows easy access (feasibility) to the electronics to improve performance: "You're gonna want to get it back apart, right?" Yori affirms their PVC design will have a "seal with 
one end, and then the other we can open". A few minutes later, Nelson breaks the $4^{\text {th }}$ wall, interrupting Yori's presentation to focus diagnostics on the need for an O-ring at the end of the PVC tube used to access the electronic system: "Okay. So what I was saying is on that cap that's screwed on, you're probably gonna need an O-ring." Yori acknowledges his comment but continues her presentation. Twenty minutes later, at the end of the presentation, Nelson drives to repeat his concerns about the feasibility of the current silicone solution in maintaining a watertight seal and providing easy access for troubleshooting system performance:

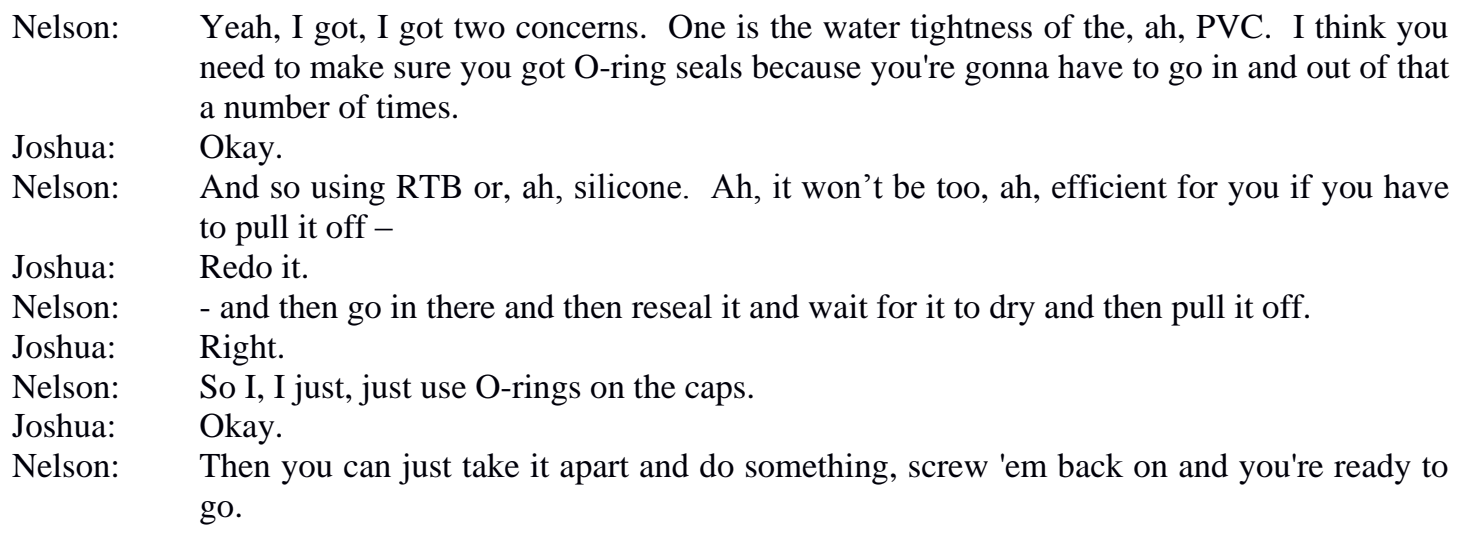

Nelson denies the effectiveness of the current solution and models his reasoning by explaining that "you're gonna have to go in and out of that (the PVC) a number of times" and how using silicone "won't be too, ah, efficient for you if you have to pull it off - and then go in there and then reseal it and wait for it to dry". He encourages students to iterate, and suggests "just use O-rings on the caps" that will allow continual access to the electronics (easy to make) while maintaining a watertight seal (feasibility). Joshua appears to understand Nelson's guidance by finishing off Nelson's statement (Yes, and) of "it won't be too, ah, efficient for you if you have to pull it off" with "Redo it".

There were similar examples in the industrial design context. For example, during Todd's first review, the instructor, Gary, drives to help Todd select five ideas for further development. Through coaching and modeling Gary guides Todd to make selections informed by design judgment principles (e.g., novelty, aesthetics, interactivity and unpredictability) and a risk management strategy Gary uses when "working in innovation". Gary calls this strategy "the illusion of choice" and he uses it to gain a client's attention by demonstrating variations from the "safe" to the "really extreme", so a designer has a safe option "you can fall back on".

These examples illustrate how coaches can take control of a review dynamic, driving to guide students in their decision-making. From a learning perspective, Sawyer (2004) argues that driving should be discouraged since it can break a constructivist interaction structure. However, observations of coach driving co-occurred with cognitive apprenticeship techniques (most notably modeling and scaffolding) and were directed at helping students make conceptual connections, see fallacies in their design thinking, or broaden the space of alternatives for addressing problematic situations. Even though driving commonly co-occurred with breaking the $4^{\text {th }}$ wall, it was just as likely to co-occur 
with suggest don't tell; in essence, a coach would take control of a design review interaction while also encouraging students to take control of their design decisions. While occurrences of driving were relatively distributed across design judgment codes, it was often directed towards helping students manage time and complexity.

This pattern complements other research from this dataset that characterizes design coaching as "directed recommendations" (Yilmaz \& Daly, this issue) and how coaches drive the complexity within design reviews (Howard \& Gray, 2014; Cardoso, Eris \& Badke-Schaub, 2014). This pattern was frequently observed in these two contexts except for final reviews where emphasis switched from providing guidance to evaluating final designs. In mechanical engineering the students performed their review and the coach entered by initializing, interrupting, or concluding the presentation. In industrial design the coach sat by the student in a one-on-one conversation that did not seem to have a set time or structure but rather flowed to an undefined end point. In choreography, this pattern may be implicit through the formal turn-taking review structure.

From a PCK perspective, driving for meaning and guidance may be an alternative to the scaffolding articulation pattern; both appear to be directed at understanding how students think or the difficulties they may encounter, yet differ in their approaches for affecting learning. For the mechanical engineering example, the instructor may have experienced his repeated attempts to bring students' attention to problems with the PVC seal as a form of resistance (e.g., Yori may have been unwilling or unable to understand the feedback). This may explain why he drives the review and does not directly critique the current solution, but rather offers the O-ring alternative to make visible the limitations of the silicone solution. For industrial design, the instructor may have perceived the student as a beginning designer needing explicit directed guidance, what McDonnell (this volume) observed as "prescripted instruction".

\subsection{Breaking the $4^{\text {th }}$ wall to create a teaching moment}

Breaking the $4^{\text {th }}$ wall occurs when a coach breaks a coach-student interaction to communicate an important point such as a concept, ground rule, or strategy that has intrinsic value for the coach or the field of inquiry. When used with other techniques like scaffolding ( $48 \%$ co-occurrence), modeling ( $31 \%$ co-occurrence), and coaching (18\% cooccurrence) it was observed to take the form of a "teaching moment" that made visible the ways a coach seeks to convey design thinking knowledge students may find unfamiliar, abstract, counterintuitive or in conflict with prior beliefs, or difficult to recognize as central to designing and becoming a designer - such as iteration, reflection, and time and risk management. This pattern was observed in all review contexts and took two forms - situated and intentional. Most examples, like the choreography example below, were situated teaching moments where a coach was opportunistic with scaffolding, modeling or coaching in-the-moment on a particular issue. The intentional form was observed in the mechanical engineering context when the instructor made an explicit effort to meta-communicate concepts of intrinsic value to the coach and possibly the discipline - time management, feasibility, and cost.

The choreography scenario "ideas are generative, right?" illustrates a situated teaching moment where Rachel (coach) breaks the $4^{\text {th }}$ wall to convey and encourage problem 
framing in relation to coherence and aesthetics; focused diagnostic troubleshooting for aesthetic, feasibility, and usability issues; and iterative and reflective practice. It occurs in Elena's (student) second review where Rachel coaches her on the coherence and aesthetics she enjoyed in the cast's performance: 'I'm enjoying watching your dancers...I really liked your cast, like the way they are all together...a lot of these gestures that sort of have something to do with like the head or like things coming out of the head or like I'm really enjoying those." Rachel then breaks the $4^{\text {th }}$ wall to create a teaching moment on the ways reflective practice and iterative co-evolution can bring problem framings and solutions into greater alignment, modeling why iterations occur and how iterative reflective practice can enable greater coherence between problem framings and solutions:

Rachel: I think you're in - you're your situation, your optional situation right now is that you started with an idea that generated movements and generated your staging and everything. Um, and I think that what happens is we work and then we create something and that thing speaks, and I don't think it's necessarily saying like straight your ideas that generated it. So for me, the optional situation, and then seeing women like half-dressed in underwear, I like I don't understand what you're trying to tell me and I don't go to the place that you started from. And I'm not advocating for you pushing your piece in the direction of the ideas you started from, because ideas are generative, right.

Rachel coaches Edite that "you're in...your optional situation right now" and how she "started with an idea that generated movements...staging and everything" that makes up a design. She models how reflective practice involves listening to a situation's back talk (Schon, 1993): "what happens is we work and then we create something and that thing speaks, and I don't think it's necessarily saying like straight your ideas that generated it". Rachel scaffolds Elena's attention to a perceived lack of coherence: “...then seeing women like half-dressed in underwear...don't understand what you're trying to tell me and I don't go to the place that you started from". She models reflection and iteration by explicitly articulating how she is "not advocating" for any particular solution (suggest don't tell), but rather encouraging Elena to take this moment to consider how "ideas are generative."

As the review continues, Rachel repeatedly scaffolds focused diagnosis on a lack of coherence of the choreography with the problem frame: "because these ideas about pulling the clothes may not have anything to do with your ideas about worry, right?" She again encourages Elena to critically reflect and iterate - to be open to changing her initial "preconceived notions", taking feedback from the piece itself, and listening to the way the design wants to evolve - to either "push it towards" the original idea or "follow the flow":

Rachel: $\quad$ But the piece is maybe calling for that to happen. So you just get to decide, like do I kinda stick and like, and like go into like I want it to be like this, and make changes and push it more towards an original idea or do you flow with like what is happening and go, you know, I can let go of some of my preconceived notions and follow the flow."

Rachel repeats this pattern multiple times - breaking the $4^{\text {th }}$ wall to model reflective and iterative practice, scaffold focused diagnostics on aesthetics and coherence, and coach 
Elena to step back, reflect and iterate to bring her intentions and choreography into greater alignment. She ends her review by acknowledging how this kind of design thinking may be difficult and suggests Elena explore other titles for her piece that improve alignment between her intentions and her choreography: "So I think it's really hard to step away from your work and just ask it, you know, kinda like, well, what are you doing, already, work, and how can I help bring that to fruition. Because I think it for me, I think it has a different title than, than how you've got it right now."

There were similar examples focusing on different concepts in the industrial design reviews. During Todd's first review, Gary broke the $4^{\text {th }}$ wall to communicate how formalizing the ergonomics of a design sketch can enable reflection and iteration. Gary coached Todd to put his ideas "in scale" before committing to his top design choices. He encouraged deep modeling strategies such as scaling up a sketch into dimensions that meet "ergonomic seating requirements" to inquire into the ways formalizing a design retains or loses aesthetic or innovative qualities: "put it 'em into height, width, function, and then as designers it still meets your aesthetic needs of, of being innovative." Gary modeled how "you may lose the essence - design essence and what you're passionate about. Formalizing it may just all go away" and how this may "lead you (to) a better solution".

The intentional form of this pattern is illustrated through the mechanical engineering scenario, "So why did you not stay on schedule?" After the mechanical engineering final reviews, the coach engaged the entire class in a debrief session to help students connect their recent design experience to the nature of professional practice. This occurred in a traditional classroom setting with students seated in rows and the instructor at the front of the room, sometimes at the podium and sometimes roving the front of the room. After a general discussion, Nelson breaks the $4^{\text {th }}$ wall to take students on a reflective practice journey - scaffolding reflection through structured questions that guide the class to articulate and reflect upon how and why they didn't stay on schedule, and modeling his perspective on the relationship between time management and good design practice. As students respond, Nelson uses Yes, and to affirm students comments and revoice them in terms of time and complexity management strategies. Lande \& Oplinger (2014) describe this as a Socratic dialogue in which the coach "pulled along" the students to understand design thinking concepts.

First, Nelson scaffolds students to reflect on how the "schedules in the back of your book are red, right?" and then asking, "Why did you do that?" Doug, from the Robot Fish team explains, "the schedule's super idealistic, and it's very, very, very hard to keep up with." Nelson pushed for additional reflection, noting that from his perspective, the schedule is "easy to keep up with". He continues, "Alright so why did you not stay on schedule? I mean, really." Some students responded, explaining how complexity management impacts time management - how "getting behind schedule" with fabricating parts is "not gonna work on the first try...need a week or two weeks to really test everything." Nelson used Yes, and to build on assertions and explain how "the complexity of the different phases" means you "adjust for that...that's a good idea" and how "we underestimate things...Especially things we haven't done before." This 
combination of scaffolding articulation with Yes, and techniques continues for about six minutes and Nelson breaks the $4^{\text {th }}$ wall again to model his perspective on the nature of professional practice - the criticality of achieving technical performance (feasibility), and staying with cost (feasibility), and being able to maintain a schedule (time management):

Nelson: $\quad$ All right, so what - the three things - you're exactly right. The schedule went red. That's kind of important, and I didn't grade on your schedule being red, because I anticipated that and I want to make this point because I want to - give you the best service I can for your next job. That's really where I'm going with this. An engineer has responsibilities for three things - in industry. One is technical performance. If you don't get technical performance, you don't have anything you're out of a job, right? That's the same way here. You had to have some minimum technical performance to continue. Secondly, what's - next most important is schedule, and thirdly, is cost. And schedule is the second most important thing because if we stay on schedule or, or ahead of schedule, you contain your costs. Costs are built on the schedule when you, when you lay it out, and if you go beyond the schedule, the costs ex-, ah, ah, go up, and things get really bad. Now in industry, they generally can accept technical performance and on-schedule and over cost to some degree. They can accept that. What they cannot accept is non-technical performance, and what they generally do not accept is going over schedule, because then you - go over schedule and you increase costs. And they usually allow you to do that once before they take you out of the equation. So that's a really important thing is just to stay on schedule.

Nelson continues scaffolding articulation with: "Now none of you stayed on schedule. Clear up until the end, essentially. So why did you not correct for that?" Chris articulated how "each step took exponentially more time and more effort...And it just got like bigger and bigger and bigger...harder and harder -." Nelson's completes Chris' sentence (Yes, and), "- harder and harder to catch up?" and acknowledges how "once you get behind schedule, it gets exponentially harder to catch up. That is the norm." Nelson explained how problems cascade and Kristen connects this to her experience: "you find one problem, and then another one arises right as you solve that one." This conversation continues for another few minutes and then Nelson breaks the $4^{\text {th }}$ wall to repeat his coaching goal:

Nelson: $\quad$ Anybody else? Okay, so here's, here's the issue. When you're in industry, here - we did the way we did it here. And, of course, this is maybe the first time that you had to try and meet a schedule under difficult situations. But in industry, this would not be acceptable. If I was in industry and you were working for me as program manager, you'd only do this once, and then I would not allow you to be in that position again... So the thing you need to take away from this class, or just two things, one is the process we use, it's one that's generally used in industry everywhere, but with a [preliminary design review] and [conceptual design review], now they call 'em different things, but they're generally used in industry. And the process we use - so it's a pretty robust process, mission statement, performance criteria, design criteria. It's a very robust process. So it automatically leads you to success - if you follow the process. But the other thing you have to take away from this is you must follow that process within the schedule. Because those are the two things that are going to get you in trouble. If you don't follow the process, you won't get technical performance. And if you don't stay within schedule, you'll be costing me money and I won't allow that to happen a second time.

These key messages ground Nelson's intentions in creating an authentic experience for his students based on his perspective of critical capabilities central to design practice - 
time management, complexity management, and meeting technical performance and cost requirements (feasibility) - as well as the consequences of not staying on schedule.

These examples illustrate how coaches interrupt a review dynamic to intentionally or opportunistically meta-communicate knowledge of design practice and habits of mind. From a PCK perspective, this pattern makes visible coaches' design knowledge in relation to knowledge about design concepts students may find unfamiliar, abstract, counterintuitive, in conflict with prior beliefs, or difficult to recognize as central to design practice. This supports research on the use of teaching as improvisation techniques where "breaking the $4^{\text {th }}$ wall" provides structure for teachers to meta-communicate a concept students may find difficult (Kang, Brian \& Ricca, 2010). For example, Rachel meta-communicated the reflective and iterative aspects of design thinking that research indicates students have difficulty understanding or valuing as effective practice (Adams \& Fralick, 2010) but represent key performance dimension of design thinking (Adams, Turns \& Atman, 2003; Dorst \& Cross, 2001; Crismond \& Adams, 2012; Schön, 1993). Similarly, Nelson and Gary meta-communicated key messages about design practice based on their own experience-based knowledge - time management (how and why projects go off schedule, and the associated consequences) and deep modeling (how formalizing a design retains or loses important qualities).

This pattern also illustrates coaches' intertwined knowledge of design with knowledge of ways to affect student learning. Just as designers use opportunistic and flexible strategies during design (Ball \& Ormerod, 1995; Radcliffe \& Lee, 1998), design coaches were opportunistic and adaptive in their approach to coaching, opportunistically leveraging reflection-in-action in-the-moment and intentionally creating meta-discussion (Cennamo, et al., 2011) and reflection-on-action opportunities (Schön, 1993). Coaches combined teaching techniques to help students make connections between their design experience and the nature of design - e.g., encouraging problem framing and focused diagnostics in relation to coherence and aesthetics in the choreography review, combining scaffoldingarticulating-modeling-Yes, and in the final mechanical engineering debrief to help students articulate the tacit features of their recent experience, and encouraging deep modeling in the industrial design review to help a student learn through discovery the negative and positive outcomes of formalizing a design sketch. In the process, coaches made visible their perspectives of core aspects of design thinking and practice.

\subsection{Suggest don't tell to let the student figure it out}

This final pattern illustrates the ways coaches make visible a tolerance for ambiguity by offering students alternative perspectives and encouraging them to make their own informed design decisions (suggest don't tell). This is indicated in coaches' soft suggestions of "play around with that", "just to explore that", and "you might check that". This pattern was observed across all contexts, and typically involved combining teaching techniques - scaffolding ( $18 \%$ co-occurrence), modeling ( $23 \%$ co-occurrence), driving (18\% co-occurrence), and breaking the $4^{\text {th }}$ wall (18\% co-occurrence)) - to guide students onto a pathway of discovery and self-expression, referencing all design judgment, task strategy, and process management strategy codes. 
In some cases coaches actively challenged a student's prior beliefs and conceptions, providing examples and other scaffolding to help a student understand the consequences of design decisions or imagine other possibilities. This is illustrated in the following industrial design scenario, "He's gotta discover that". Todd's fourth review involved selecting a final idea and building a "looks like" model - a full-scale semi-functional prototype to communicate a final design to the client. This was the last review before final client presentations. It occurred at Todd's workstation, part of a long table of six student workstations each with two monitors. Gary is sitting to Todd's right. It begins with Todd denying Gary's critique on the feasibility of a rotating ottoman design, and then Gary breaking the $4^{\text {th }}$ wall to create a teaching moment, modeling the strategies of valid testing of feasibility and deep modeling to inquire into how his design might be built. While Gary could have simply told Todd the design wouldn't work and that he should do something else, he consistently suggests but doesn't tell Todd what to do, providing scaffolding to help Todd make his own decision based on informed reasoning and experimentation.

<<Figure 3 about here, shown in text to show desired dimensions $>>$

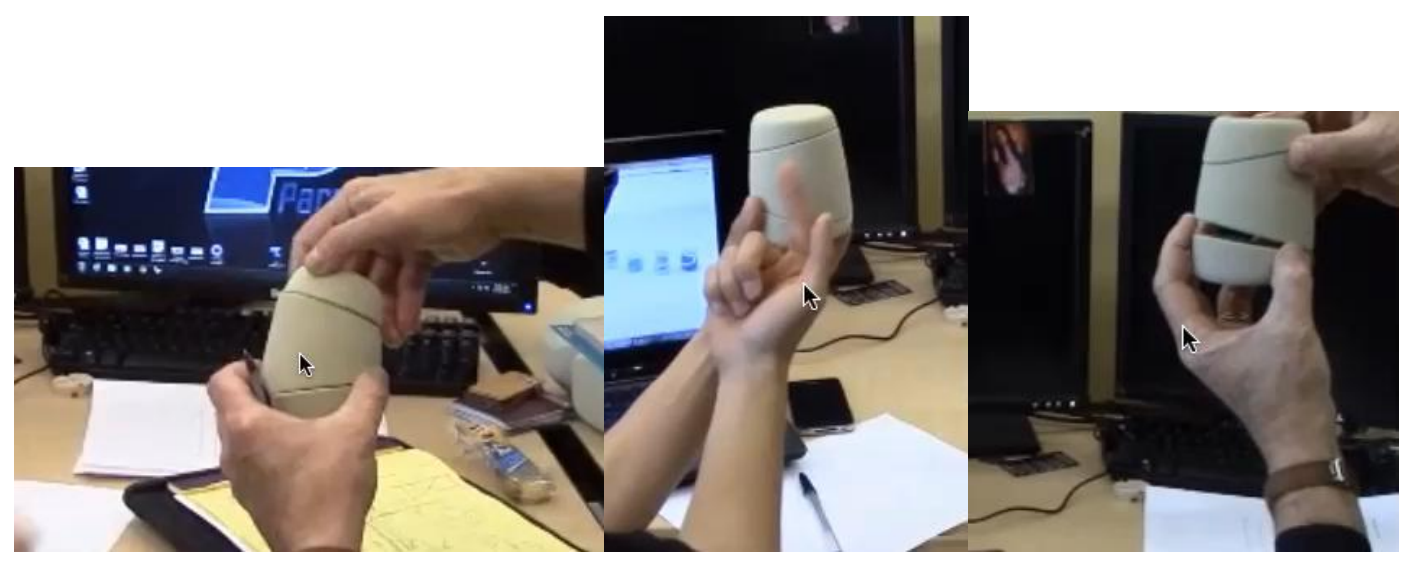

Figure 3. Todd's rotating ottoman design from three perspectives: (a) far left, the foam model as three rotating pieces (Gary's hands), (b) middle, Todd's explanation of a single perpendicular axis (Todd's index finger), and (c) far right, Gary's explanations of the consequences of a single perpendicular axis (Gary's hands).

Todd's ottoman design involves three separate but independently moving diagonal segments that allow a user to change the incline of the seating area by rotating the segments (Figure 3a). Todd articulates his rationale for selecting this design because the client felt it was "more pure" (aesthetic) and interactive: "[they] want it to rotate. That's the thing they kept talking about". Todd shows Gary a 3D foam model, and explains that a single perpendicular axis up the center will allow the segments to spin (Figure 3b): "it's gonna basically a pole coming out of it...fit on top of that hole that's coming out like this right? And then that can spin on the axis". Gary quickly focuses diagnosis on a feasibility issue: 
Gary: $\quad$ But keep in mind, though, if you have just one center axis, you sure you're not gonna have to have a second axis? Because what happens is this is going straight through here what can really - you're already locked in.

Todd: $\quad$ Will I be?

Gary: Well, what we'll see, get a pencil and ah, ah, see, that's what I'm thinking's gonna happen.

Gary explains how the ottoman segments are on different planes and will require more than one axis of rotation. Todd asserts, because this "plane is perpendicular...I can rotate it like anywhere." Gary uses Yes, but to acknowledge Todd's assertion while also rejecting his reasoning, and then models strategies for conducting valid tests: "get a dowel rod and drill through all these and see what you think". Gary suggests that Todd "play with it" to discover what will happen. Over the next few minutes, Gary encourages Todd to develop valid tests and use deep modeling to inquire into the feasibility of how his design will perform. A couple minutes later, Gary breaks the $4^{\text {th }}$ wall to offer advice on bounding the scope of work (complexity management): "don't overcomplicate yourself...it needs to be a 'looks like' it doesn't need to be a function...it's just you just need to do enough to show it, the function of it." He models his reasoning by explaining how the effort of creating a fully working prototype "will take away from your schedule. It'll take away from your electronic presentation."

When the discussion returns to the mechanics of the rotating design, Alek (a student on Todd's left) joins the interaction asserting how the rotating idea won't work: "It's not gonna spin with the dowel. Not with the angles." Todd disagrees, and Gary breaks the $4^{\text {th }}$ wall to suggest but not tell that Todd has "gotta discover that." He coaches Todd to experiment and figure it out for himself. Todd continues to resist the concerns about his design saying, "I don't know why it wouldn't". Alek explains that he can either have the top sit flush or spin, "you can get one or the other" but not both. Gary follows by modeling what could happen, demonstrating with the foam model of the design (see Figure $3 \mathrm{c}$ ). When Todd still has difficulty seeing the issue, Gary breaks the $4^{\text {th }}$ wall to suggest but not tell Todd to experiment and figure it out for himself suggesting it will be an important learning experience: "you just need to go through it. This will be a good experience for you."

There were many examples of this pattern across contexts. In choreography, some of the ambiguity resulted from coaches offering different perspectives. A brief example was during Elena's first review. After Claire focused diagnostics on the lack of coherence between the hand movements and Elena's problem framing of mimicking the experience of riding a subway, each coach provided different feedback and suggestions such as alternative hand gestures and encouraging Elena to experience a subway. Claire took back her review turn by suggesting, but not telling Elena to explore different ways for mimicking the experience of "putting on the brake": "could [you] find other ways of that being stopped in your tracks kind of feeling, um, like what would happen if it was part of a turn and all of a sudden you stopped in the middle of the turn just to explore that you know, the brakes." In the mechanical engineering conceptual design review, Nelson scaffolds students' attention on the feasibility and coherence of the sub-system that controls the movement of the robot fish fins. Nelson repeatedly suggests, but doesn't tell 
the students to conduct valid tests on the moment placed on the servo arm by coaching, "you might check that" and "intuition tells me it's not gonna work, but - go ahead".

These examples illustrate how coaches help students manage multiple perspectives and make their own informed decisions. From a design perspective, designerly ways of knowing involve having a tolerance for ambiguity and multiple solutions (Cross, 2006), managing and preserving ambiguity (Lande \& Leifer, 2010), reasoning about uncertainty (Dym et al., 2005), and awareness of how multiple perspectives enables generative thinking (Kocaballi, Gemeinboeck, Saunders, Dong \& Loke, 2012). In this study, coaches' extensive use of suggest don't tell across contexts may be an indicator of a shared philosophy of design - design as ambiguous - that has intrinsic value for the coaches or field of design inquiry. Goldschmidt (2006) notes in a study of architectural design studios, "we find it rare for instructors to explicitly state or prescribe specific design goals... Both students and instructors expect students to define their own goals, emphasize clear concepts ('leading ideas')... an implicit underlying premise calls for selfexpression and rewards creative behavior.” (pp. 1)

Suggest but don't tell co-occurred with other patterns (most frequently with driving for meaning and guidance and breaking the $4^{\text {th }}$ wall to create a teaching moment) as well as the individual coding systems. Coaches tended to encourage students' self-expression and experimentation on issues of feasibility, aesthetics, and coherence through design strategies of problem framing, deep modeling, conducting valid tests, focused diagnostics, reflection, and iteration. While this pattern was evident in all contexts, it was more likely to be observed in the informal structures of the industrial design and choreography reviews where coach-coach and coach-student dialogue was more frequent and of longer duration.

From a PCK perspective, we observed coaches demonstrating their knowledge of design as ambiguous while engaging in an instructional dance of alternating approaches that break or drive a review dynamic to help students understand and use effective design practice with those that empower students to make their own decisions. In some cases a coach challenges a student's prior beliefs, providing examples and other scaffolding to help a student understand the consequences of design decisions or imagine other possibilities. This observation aligns with Yilmaz and Daly's (this volume) description of design coaching as giving students freedom to explore and come into their own design aesthetic while also providing enough guidance and mentorship to help them approach complex design tasks, and McDonnell's (this volume) analysis of the way Gary helped students develop their own voice as designers.

\section{The work of coaching}

In this exploratory study we used a PCK lens to characterize the work of coaching in design reviews. We consistently observed four design PCK patterns across dramatically different disciplinary contexts and review structures, indicating these patterns have broad applicability. In this section we revisit the goals of this exploratory study to summarize three insights regarding the work of coaching in design reviews: coaching as integrated knowing, situated practice, and shared repertoires. 


\subsection{Integrated knowing}

Prior research on the work of coaching tends to focus on single dimensions such as roles (Goldschmidt, Hochman \& Dafni, 2010; Marin et al., 1999; Pembridge, 2011; Taylor et al., 2001), instructional strategies (Brandt et al., 2013; Cennamo et al., 2011; Dannels \& Martin, 2008; Dym et al., 2005; Ledewitz, 1985; Marin et al., 1999; Schön, 1993; Uluoğlu, 2000), or review structures (Goldschmidt, Hochman \& Dafni, 2010; Oh et al., 2012). By using a design PCK lens this study broadens this work by making visible the work of coaching as integrated knowing, intertwining an understanding of design, students, and ways to affect student learning (see Table 1 and Figure 2).

We observed coaches' understanding of design as integrating conceptual and procedural knowledge. For each design PCK pattern, coaches directed students' attention towards the full breadth of conceptual and procedural knowledge frameworks - design judgment, task strategy, and process management strategy codes. All coaches utilized all codes, although in different ways (see Carvalho, Dong \& Maton, 2009). Choreography instructors emphasized aesthetics and coherence, but also referenced feasibility regarding human capabilities in dance. The industrial design instructor emphasized aesthetics and interactivity, and emphasized novelty early in the process but feasibility later; and the mechanical engineering instructor emphasized feasibility, but also referenced other issues including aesthetics. Each used the coherence and (un)predictability codes, but differently. In mechanical engineering, coherence referred to linking system complexities and producing a complete integrated solution; in choreography and industrial design, coherence often referred to the integration of form and function. In choreography and industrial design, students were encouraged to integrate unpredictability into their designs to create drama or surprise; in mechanical engineering, the instructor encouraged predictable solutions that guaranteed performance. Finally, the industrial design and mechanical engineering instructors emphasized risk, time, and complexity management strategies in ways that emphasized their personal professional experience. Coaches also seemed to share a philosophy of design as having a tolerance for ambiguity (Cross, 2006): they all suggested but didn't tell students what to do - they would draw attention to problematic situations and provide multiple perspectives, and then encourage students to experiment and make their own judgment.

We observed coaches' intertwined understanding of design and how students think about, know, or learn design. Coaches conveyed or demonstrated design knowledge to help students notice and interpret problems, identify and address key decision points, articulate and examine the consequences of design decisions, and make visible their views on design thinking. Coaches repeatedly emphasized particular kinds of design knowledge, suggesting they had particular concerns about their students or key messages to convey about design practice. Coaches repeatedly encouraged focused diagnostics, which suggests they perceived students needed extensive guidance with diagnosing their ideas, processes, and alignments between current solutions and problem framings. As shown in the examples, coaches used focused diagnostics like "generative sensing" in which a coach begins with evaluating a student's design and then switches from deductive to abductive reasoning to sharpen or loosen up the problem frame (Dong, Garbuio \& Lovallo, 2014). Coaches also repeatedly emphasized iteration and reflective 
practice often in combination with problem framing, deep modeling, valid testing, and time and complexity management.

We observed coaches' intertwined understanding of design and issues that affect design learning. Coaches combined, repeated, and modified their strategies (at times taking control and at other times giving up control) to unpack elements of design and make its features apparent to students (Ball et al., 2005). For example, the mechanical engineering coach took control of the Robot Fish presentation and used a variety of techniques to drive students towards addressing his concern of "you're gonna need an O-ring" - at times modeling his own reasoning, using scaffolded articulation to have students explain their reasoning, providing coaching on how the current solution may not perform well, and breaking the $4^{\text {th }}$ wall to bring attention back to the original concern. Coaches also created learning opportunities, intentionally or situated in-the-moment, to help students reflect on and critically examine their design experience as an ongoing process of learning to become designers.

\subsection{Situated practice}

Similar to Goldschmidt (2006), we observed the work of coaching as having a just-intime quality, rather than a set script. Goldschmidt (2006) described the process of translating and conveying knowledge to students as highly adaptive to the student and situation, rather than a place of teacher-directed synthesis or decontextualized teaching scripts. This supports our use of the teaching as improvisation framework to code coaching actions, where teachers as expert improvisers use guiding questions to focus students on concepts relevant to the situation at hand (Kang, Brian \& Ricca, 2010). We observed coaches being consistent with their practice and key messages as well as tailoring their coaching to meet the demands of the situation, an observation other researchers noticed in this dataset (Cardella et al., 2014; Ferreira, Christiaans \& Almendra, 2014). All of these indicate the work of coaching as situated practice - where coaches draw on their repertoire to respond to the situation at hand and likely use these experiences to expand their accumulated wisdom. One feature of this situated practice is that coaches both take and give control during a design review, walking a line between driving students in a particular direction and encouraging students to act independently. As shown in Table 7, the patterns of driving for meaning and guidance and breaking the $4^{\text {th }}$ wall to create a teaching moment, and to a certain extent scaffolded articulation, are actions taken on the part of a coach to drive deeper inquiry and understanding by pushing students to explain their reasoning, make conceptual connections, and overcome limitations or fallacies in their design thinking. In contrast, the patterns of suggest don't tell to let the student figure it out involves a coach empowering a student to act independently and make their tacit reasoning explicit and open to critical reflection. By using cognitive apprenticeship and teaching as improvisation frameworks together, another aspect of coaches' situated practice emerged: our coaches traversed a space of who does the work of making thinking visible (coach or student), whose thinking or practice is made visible (and to whom), and who is driving a design review conversation (coach or student). 


\subsection{Shared repertoire}

Another study goal was to observe the work of coaching across contexts and review structures. Three of the four patterns were evident across all contexts and review structures, although features of review structures may enable different types of coachstudent interactions. Also, almost every code was observed in every context or review structure. This suggests the coaches in this study share a repertoire of teaching techniques (cognitive apprenticeship and teaching as improvisation) and design thinking knowledge (design judgment, and task and process management strategies). By providing a common language (the codes and patterns), the observed repertoires can be used to support coaches (newcomers and oldtimers) in making sense of their experiences and reflecting on their practice, moving tacit experiences into the realm of explicit design PCK strategies. Sharing repertoires may spark coaches' interest in trying out new approaches and learning from others, enabling collaborative inquiry and a renewal of design coaching practice.

\section{Conclusions and future work}

This study was a first step in taking an integrated approach to characterize the work of coaching in design reviews. One goal was to integrate learning sciences frameworks with design frameworks to enable conceptual bridges between the nature and nurture of design thinking. Another was to leverage the benefits of the PCK construct (Mishra \& Koehler, 2006) to advance research on the work of coaching in design reviews and frameworks that support the professional development of coaches, and facilitate research-to-practice connections.

We observed four patterns of design-specific approaches to coaching (design PCK) using a set of coding schemes that give language to what coaches do and how what they do conveys or reflects an understanding of design, design learners, and effective design instruction. These findings also provide alternative but complementary perspectives regarding coach strategies, functions and roles, contributions, the structure and discourse of design reviews, and the ways coaches use design reviews to support student learning and identity formation. Through these observations we identified three pathways to broaden theoretical conceptualizations about the work of coaching - integrated knowing, situated practice, and a shared repertoire. Design researchers could build on these ideas and bring in other methodologies that provide direct access to coaches' design PCK. For example, this study is limited to video-based observations; knowledge elicitation studies, such as using critical incident interviews and talk alouds during design review performance tasks, could provide more direct access to coaches' reasoning or past experiences that shaped their approaches to coaching. Also, this study uses only a portion of the full dataset; expanding this study to include the full dataset could further test applicability of findings across contexts.

From the perspective of advancing knowledge of design instruction and coach professional development, the patterns and coding schemes provide a language for sharing, discussing, critiquing, and reflecting upon what happens during a design review and what coaches do to facilitate learning. By providing a language for noticing, this 
study can help design coaches make sense of their experiences in ways that support reflective practice, moving tacit experiences into the realm of explicit design PCK strategies. This can help build personal repertoires that synergize design thinking knowledge, understandings of design learners, and design thinking specific teaching techniques - repertoires that can be flexibly applied in the moment-by-moment work of design teaching. By learning through and with others, coaches can reflect on what may be present or missing in their own coaching work with students. Finally, by taking an integrated perspective to the work of coaching that connects perspectives on the nature of design to the nurture of design learning, we have assured that discussions of design thinking are relevant to design coaching, and that discussions of design coaching retain attention to design thinking.

\section{Acknowledgements}

The authors graciously thank the individuals who shared their design review experiences. This work was supported by grants from the National Science Foundation (EEP0748005) and the Purdue Global Engineering Program International and Global Impact program.

\section{References}

Adams, R.S. and Siddiqui, J. (Eds.) (2015). Analyzing Design Review Conversations. West Lafayette, IN: Purdue University Press.

Adams, R.S. (2015). Design Review Conversations: The Dataset. In R.S. Adams \& J. Siddiqui (eds), Analyzing Design Review Conversations (Chapter 2). West Lafayette, IN: Purdue University Press.

Adams, R. S., Forin, T., Chua, M., \& Radcliffe, D. (2014). "Making design pedagogical content knowledge visible within design reviews." Paper presented at Design Thinking Research Symposium. West Lafayette, IN: $\quad$ Purdue University. Paper retrieved from http://docs.lib.purdue.edu/dtrs/2014/Authority/1/

Adams, R. S., Turns, J. \& Atman, C. J. (2003). "Educating effective engineering designers: The role of reflective practice.” Design Studies, 24(3), pp. 275-294.

Anderson, J. R. (1976). Language, memory, and thought. Mahwah, NJ: Erlbaum.

Andjomshoaa, A., Islami, S.G. \& Mokhtabad-Amrei, S.M. (2011). "Application of constructivist educational theory in providing tacit knowledge and pedagogical efficacy in architectural design education: A case study of an architecture school in Iran.” Life Science Journal, 8(1), pp. 213-233.

Argyris, C. \& Schön, D. A. (1974). Theory in practice: Increasing professional effectiveness. San Francisco: Jossey-Bass.

Attoe, W. \& Mugerauer, R. (1991). “Excellent studio teaching in architecture". Studies in Higher Education, 16(1), pp. 41-50.

Ball, D.L., Thames, M.H. \& Phelps, G. (2005). Content knowledge for teaching: What makes it special?

Ball, L. J., \& Ormerod, T. C. (1995). "Structured and opportunistic processing in design: A critical discussion." International Journal of Human-Computer Studies, 43, 131-151.

Baxter Magolda, M.B. and P.M. King (2004). Learning Partnerships: Theory and Models of Practice to Educate for Self-Authorship. Stylus Publishing, Sterling, VA.

Beghetto, R. A. (2009). "In search of the unexpected: Finding creativity in the micromoments of the classroom." Psychology Of Aesthetics, Creativity, And The Arts, 3(1), pp. 2-5.

Brandt, C., Cennamo, K., Douglas, S., Vernon, M., McGrath, M. \& Reimer, Y. (2013). "A theoretical framework for the studio as a learning environment". International Journal of Technology \& Design Education, 23(2), pp. 329-348. 
Borko, H. and Livingston, C. (1989). "Cognition and Improvisation: Differences in Mathematical Instruction by Expert and Novice Teachers." American Educational Research Journal, 26(4), pp. 473498.

Brennan, K. A. (2013). Best of both worlds: Issues of structure and agency in computational creation, in and out of school. Doctoral dissertation, Massachusetts Institute of Technology.

Cardella, M. E., Buzzanell, P. M., Cummings, A., Tolbert, D., \& Zoltowski, C. B. (2014). "A tale of two design contexts: Quantitative and qualitative explorations of student-instructor interactions amidst ambiguity.“ Paper presented at Design Thinking Research Symposium. West Lafayette, IN: Purdue University. Paper retrieved from http://docs.lib.purdue.edu/dtrs/2014/Authority/2/

Carvalho, L., Dong, A. \& Maton, K. (2009). "Legitimating design: a sociology of knowledge account of the field. Design Studies, 30, pp. 483-502.

Cennamo, K., Brandt, C., Scott, B., Douglas, S., McGrath, M., Reimer, Y. \& Vernon, M. (2011). "Managing the complexity of design problems through studio-based learning". Interdisciplinary Journal of Problem-based Learning, 5(2). http://dx.doi.org/10.7771/1541-5015.1253

Chi, M. T. H., Glaser, R., \& Farr, M. J. (1988). The nature of expertise. Hillsdale, NJ: Lawrence Erlbaum Associates.

Collins, A., Brown, J. S., \& Holum, A. (1991). Cognitive apprenticeship: making thinking visible. American Educator, 6, 38-46.

Crismond, D. and Adams, R.S. (2012). "The Informed Design Teaching and Learning Matrix". Journal of Engineering Education, 101(4), pp. 738-797.

Cross, N. (2006). Designerly Ways of Knowing. London: Springer-Verlag.

Daly, S., Adams, R.S., and Bodner, G. (2012). "What does it mean to design? A qualitative investigation guided by design professionals' experiences." Journal of Engineering Education, 101(2), pp. 187-219.

Dannels, D. P. (2005). Performing tribal rituals: A genre analysis of 'crits' in design studios. Communication Education, 54(2), 136-160.

Dannels, D., Gaffney, A. H. \& Martin, K. N. (2008). Beyond content, deeper than delivery: What critique feedback reveals about communication expectations in design education. International Journal for the Scholarship of Teaching and Learning, 2(2), article 12. http://digitalcommons.georgiasouthern.edu/ijsot1/vol2/iss $2 / 12$

Dorst, K. \& Cross, N. (2001). "Creativity in the design process: co-evolution of problem-solution." Design Studies, 22 (5), pp. 425-437.

Dreyfus, H., \& Dreyfus, S. (1985). Mind over machine: The power of human intuition and expertise in the era of the computer. New York: Free Press.

Dreyfus, H.L. \& Dreyfus, S.E. (2005). "Expertise in Real World Contexts.” Organizational Studies, 26, pp. 779-792.

Driel, J.H., Verloop, N. \& Vos, W.d. (1998). “Developing science teacher's pedagogical content knowledge." Journal of Research in Science Teaching, 35(6), pp. 673-695.

Dym, C.L., Agogino, A.M., Eris, O., Frey, D.D. and Leifer, L.J. (2005). "Engineering design thinking, teaching, and learning." Journal of Engineering Education, Jan, pp. 103-120.

Ferreira, J., Christiaans, H., \& Almendra, R. (2014). "Design grammar-A pedagogical approach for observing teacher and student interaction." Paper presented at Design Thinking Research Symposium. West Lafayette, IN: Purdue University. Paper retrieved from http://docs.lib.purdue.edu/dtrs/2014/Modalities/2/

Gess-Newsome, J. (1999). Pedagogical content knowledge: An introduction and orientation. In J. GessNewsome (ed.), Examining pedagogical content knowledge: The construct and its implications for science education. Dordrecht: Kluwer Academic.

Goel, V., \& Pirolli, P. (1992). The structure of design problem spaces. Cognitive Science, 16, 395-429.

Goldschmidt, G. (2002). “One-on-One: A Pedagogic Base for Design Instruction in the Studio.” In D. Durling and J. Shackleton (eds.), Proceedings of "Common Ground" Design Research Society International Conference, Brunel University: Staffordshire University Press.

Goldschmidt, G. (2006). "Expert Knowledge or Creative Spark? Predicaments in Design Education." Proceedings of the $6^{\text {th }}$ DTRS Symposium, Sydney, AU.

Goldschmidt, G., Hochman, H. \& Dafni I. (2010). The design studio crit: Teacher student communication. Artificial Intelligence for Engineering Design Analysis and Manufacturing, 24(3), 285-302.

Goldschmidt, G., Casakin, H., Avidan, Y. and Ronen, O. (2014). "Three studio critiquing cultures: Fun follows function or function follows fun?" Paper presented at Design Thinking Research Symposium. 
West Lafayette, IN: Purdue University. Paper retrieved from http://docs.lib.purdue.edu/dtrs/2014/Comparing/2/

Grossman, P.L. (1990). The making of a teacher: Teacher knowledge and teacher education. New York: Teachers College Press.

Hill, H.C., Ball, D.L. and Schilling, S.G. (2008). Unpacking Pedagogical Content Knowledge: Conceptualizing and Measuring Teachers' Topic-Specific Knowledge of Students. Journal for Research in Mathematics Education, 39(4), 372-400.

Howard, C.D. \& Gray, C.M. (2014). "Higher order thinking in design reviews." Paper presented at Design Thinking Research Symposium. West Lafayette, IN: Purdue University. Paper retrieved from http://docs.lib.purdue.edu/dtrs/2014/Impact/4/

Huet, G., Culley, S. J., McMahon, C. A., \& Fortin, C. (2007). Making sense of engineering design review activities. AI EDAM-Artif. Intell. Eng. Des. Anal. Manuf., 21(3), 243-266. doi: $10.1017 / \mathrm{S} 0890060407000261$

Hynes, M.M. (2012). "Middle-school teachers' understanding and teaching of the engineering design process: a look at subject matter and pedagogical content knowledge." International Journal of Technology Design Education, 22, pp. 345-360.

Kocaballi, A.B., P. Gemeinboeck, R. Saunders, A. Dong and L. Loke (2012). Transformations, Enactments and Distrust in Promoting Multiplicity in Design Process. Proceedings of the Participatory Innovation Conference, Melbourne, AU.

Lande, M., \& Oplinger, J. (2014). "Disciplinary discourse in design reviews: Industrial design and mechanical engineering courses." Paper presented at Design Thinking Research Symposium. West Lafayette, IN: Purdue University. Paper retrieved from http://docs.lib.purdue.edu/dtrs/2014/Comparing/3/

Lande, M. and Leifer, L. (2010). "Incubating engineers, hatching design thinkers: Mechanical engineering students learning design through ambidextrous ways of thinking." Proceedings of the ASEE Conference, Louisville.

Lawson, B., \& Dorst, K. (2009). Design Expertise. Architectural Press.

Lidwell, W., Holden, K., and Butler, J. (2003). Universal Principles of Design. Rockport Publishers: Cambridge, MA.

Lincoln, Y. S., and E. G. Guba (1985). Naturalistic inquiry. Beverly Hills, CA: Sage.

Magnusson, S., Krajcik, J. \& Borko, H. (1999). Nature, sources and development of pedagogical content knowledge for science teaching. In J. Gess-Newsome (ed.), Examining pedagogical content knowledge: The construct and its implications for science education (pp. 95-132). Dordrecht: Kluwer Academic.

Marin, J. A., Armstrong, J. E., \& Kays, J. L. (1999). Elements of an optimal capstone design experience. Journal of Engineering Education, 88(1), 19-22.

Mezirow, J. (2000). "Learning to Think like an Adult: Core Concepts of Transformation Theory." In J. Mezirow (ed), Learning as Transformation: Critical Perspectives on a Theory in Progress (pp. 3-33). San Francisco, CA: Jossey-Bass.

Mishra, P. and Koehler, M.J. (2006). "Technological Pedagogical Content Knowledge: A Framework for Teacher Knowledge." Teachers College Record, 108(6), 1017-1054.

Murphy, K. M., Ivarsson, J., \& Lymer, G. (2012). Embodied reasoning in architectural critique. Design Studies, 33(6), pp. 530-556. doi: 10.1016/j.destud.2012.06.005

Oak, A. (2000). "It's a Nice Idea, but it's not actually Real: Assessing the Objects and Activities of Design". JADE19.1 NSEAD. 86-95.

Oak, A., \& P. Lloyd (2014). “'Wait, wait: Dan, your turn': Assessment in the design review." Paper presented at Design Thinking Research Symposium. West Lafayette, IN: Purdue University. Paper retrieved from http://docs.lib.purdue.edu/dtrs/2014/Authority/3/

Oh, Y, Ishizaki, S., Gross, M.D., and Do, E.Y. (2012). "A theoretical framework of design critiquing in architecture studios." Design Studies.

Oxman, R. (1999). "Educating the designerly thinker." Design Studies, 20, pp. 105-122.

Pembridge, J. J. (2011). Mentoring in engineering capstone design courses: Beliefs and practices across disciplines. (PhD Dissertation), Virginia Polytechnic Institute and State University, Blacksburg, VA.

Phillips, K. R., de Miranda, M. A., \& Shin, J. (2009). Pedagogical Content Knowledge and Industrial Design Education. Journal of Technology Studies, 35(2), 47-55. 
Purzer, S., Eila, N. D., \& Dick, E. C. (2014, Oct). “A cross-case analysis of disciplinary identities communicated through design reviews." Paper presented at Design Thinking Research Symposium. West Lafayette, IN: Purdue University. Paper retrieved from http://docs.lib.purdue.edu/dtrs/2014/Identity/5/

Radcliffe, D. F., \& Lee, T. Y. (1989). "Design methods used by undergraduate engineering students." Design Studies, 10(4), pp. 199-207.

Reich, Y., Ullman, G., Van der Loos, M. and Leifer, L.J. (2008). “Coaching product development teams: A conceptual foundation for empirical studies." Research in Engineering Design, January. DOI: 10.1007/s00163-008-0046-1

Ryan, G.W. \& Bernard, H.R. (2003). Techniques to identify themes. Field Methods, 15 (1), 85-109.

Sawyer, K. (ed) (2011). Structure and Improvisation in Creative Teaching. Cambridge University Press.

Sawyer, R. K. (2008). "Learning music from collaboration." International Journal of Educational Research, 47(1), pp. 50-59.

Sawyer, K. (2004). "Improvised Lessons: Collaborative discussion in the constructivist classroom." Teaching Education, 15(2), pp. 189-201.

Schön, D. A. (1987). Educating the reflective practitioner: Toward a new design for teaching and learning in the professions. San Francisco: Jossey-Bass.

Schön, D. A. (1993). The Reflective Practitioner: How Professionals Think in Action Basic Books, New York.

Shulman, L. S. (1986). Those who can understand: Knowledge growth in teaching. Educational Researcher 15(2), 4-14.

Shulman, L. (1987). Knowledge and teaching: foundations of the new reform. Harvard Educational Review $57(1), 1-22$.

Star, J.R. (2000). “On the Relationship Between Knowing and Doing in Procedural Learning." In B. Fishman \& S. O'Connor-Divelbiss (Eds.), Fourth International Conference of the Learning Sciences (pp. 80-86). Mahwah, NJ: Erlbaum.

Taylor, D. G., Magleby, S. P., Todd, R. H., \& Parkinson, A. R. (2001). Training faculty to coach capstone design teams. International Journal of Engineering Education, 17(4 and 5), 353-358.

Uluoğlu, B. (2000). "Design knowledge Communicated in Studio Critiques." Design Studies, 21(1), pp.3358.

Vass, E., Littleton, K., Miell, D., \& Jones, A. (2008). "The discourse of collaborative creative writing: Peer collaboration as a context for mutual inspiration." Thinking Skills and Creativity, 3(3), pp. 192-202.

Veal, W.R., Tippins, D.J. \& Bell, J. (1998). "The Evolution of Pedagogical Content Knowledge in Perspective Secondary Physics Teachers." Paper presented at the annual meeting of the National Association for Research in Science Teaching, San Diego, CA. 